\title{
2017 ERS/ATS standards for single-breath carbon monoxide uptake in the lung
}

\author{
Brian L. Graham , Vito Brusasco², Felip Burgos ${ }^{3}$, Brendan G. Cooper ${ }^{4}$, \\ Robert Jensen ${ }^{5}$, Adrian Kendrick ${ }^{6}$, Neil R. Maclntyre ${ }^{7}$, \\ Bruce R. Thompson ${ }^{8}$ and Jack Wanger ${ }^{9}$
}

Affiliations: ${ }^{1}$ Division of Respirology, Critical Care and Sleep Medicine, University of Saskatchewan, Saskatoon, SK, Canada. ${ }^{2}$ Dept of Internal Medicine, University of Genoa, Genoa, Italy. ${ }^{3}$ Respiratory Diagnostic Center, Hospital Clínic, Institut d'Investigacions Biomèdiques August Pi i Sunyer (IDIBAPS), University of Barcelona, Barcelona, Spain. ${ }^{4}$ Lung Function and Sleep, Queen Elizabeth Hospital, University of Birmingham, Birmingham, UK. ${ }^{5}$ Pulmonary Division, University of Utah, Salt Lake City, UT, USA. ${ }^{6}$ Dept of Respiratory Medicine, Bristol Royal Infirmary, Bristol, UK. ${ }^{7}$ Pulmonary, Allergy and Critical Care Medicine, Duke University Medical Center, Durham, NC, USA. ${ }^{8}$ Allergy, Immunology and Respiratory Medicine, The Alfred Hospital and Monash University, Melbourne, Australia. ${ }^{9}$ Consultant, Rochester, MN, USA.

Correspondence: Brian L. Graham, Division of Respirology, Critical Care and Sleep Medicine, University of Saskatchewan, Saskatoon, SK, Canada, S7N 0W8. E-mail: brian.grahamqusask.ca

@ERSpublications

Updated technical standards for measuring DLCO (TtCO) including the use of rapid gas analyser systems http://ow.ly/QUhv304PMsy

Cite this article as: Graham BL, Brusasco V, Burgos F, et al. 2017 ERS/ATS standards for single-breath carbon monoxide uptake in the lung. Eur Respir J 2017; 49: 1600016 [https://doi.org/10.1183/ 13993003.00016-2016].

ABSTRACT This document provides an update to the European Respiratory Society (ERS)/American Thoracic Society (ATS) technical standards for single-breath carbon monoxide uptake in the lung that was last updated in 2005. Although both DLCO (diffusing capacity) and TLCO (transfer factor) are valid terms to describe the uptake of carbon monoxide in the lung, the term DLCO is used in this document. A joint taskforce appointed by the ERS and ATS reviewed the recent literature on the measurement of DLCO and surveyed the current technical capabilities of instrumentation being manufactured around the world. The recommendations in this document represent the consensus of the taskforce members in regard to the evidence available for various aspects of DLCO measurement. Furthermore, it reflects the expert opinion of the taskforce members on areas in which peer-reviewed evidence was either not available or was incomplete. The major changes in these technical standards relate to DLCO measurement with systems using rapidly responding gas analysers for carbon monoxide and the tracer gas, which are now the most common type of DLCO instrumentation being manufactured. Technical improvements and the increased capability afforded by these new systems permit enhanced measurement of DLCO and the opportunity to include other optional measures of lung function.

This article has been revised according to the correction published in the November 2018 issue of the European Respiratory Journal.

This article has supplementary material available from erj.ersjournals.com

Received: Jan 042016 | Accepted after revision: July 242016

This report was approved by the ATS Board of Directors in August 2016, and endorsed by the ERS Science Council and Executive Committee in September 2016. An executive summary of these standards is available as https://oi.org/10. 1183/13993003.E0016-2016.

Support statement: This report was supported by the American Thoracic Society (grant: FY2015) and the European Respiratory Society (grant: TF-2014-19). Funding information for this article has been deposited with the Open Funder Registry.

Conflict of interest: None declared.

Copyright @ERS 2017 


\section{Background}

It has been over 100 years since Marie Krogh developed a method to measure the single-breath uptake of carbon monoxide in the lungs [1]. Her experiment was designed to show that passive diffusion could explain oxygen transfer from the alveolar gas to the pulmonary capillary blood, but the methodology became the basis of the test, now in common use, which is called diffusing capacity in North America but is more appropriately called transfer factor in Europe. The abbreviation for transfer factor or diffusing capacity of the lung for carbon monoxide used in this document is DLCO, although TLCO is an equally valid term.

A standardised clinical method of determining the diffusing capacity of the lung for carbon monoxide was described by OGILvie et al. [2] in 1957 using a tracer gas to determine both the alveolar volume and the alveolar concentration of carbon monoxide at the beginning of breath-holding. This method used the collection of discrete exhaled gas samples from which gas concentrations were measured using gas analysers that took up to several minutes to perform the measurements. In the remainder of this document we will term these "classical" systems and calculations. The instrumentation for DLCO measurement has advanced considerably since then, primarily through the use of rapidly responding gas analyser (RGA) systems with gas analysers that have a $0-90 \%$ response time of $\leqslant 150 \mathrm{~ms}$. While RGAs are capable of real-time, continuous gas analysis, most modern systems generally use this advanced instrumentation only to simulate the classical collection of discrete samples of gas in a bag and discard most of the sampled gas data. However, as discussed later, there are several aspects of DLCO measurement that can be improved markedly using all of the data provided by this continuous measurement technology.

This document and the accompanying executive summary document [3] are an update of the 2005 American Thoracic Society (ATS) and European Respiratory Society (ERS) standards [4] which, in turn, built upon previous standards $[5,6]$. This update reflects the consensus opinions of both of these societies and is designed to: 1) provide an update to the standards required for DLCO systems based on RGA systems; and 2) provide new calculation standards that incorporate continuous gas analysis of the entire exhaled sample. It is recognised that classical equipment will remain in use for some time. However, some previously designed DLCO systems can be upgraded and re-engineered to meet these new RGA system standards. It is expected that as new DLCO systems are designed and built, they will meet and, in many cases, exceed these new standards. This document is meant to function as a stand-alone work but, for certain issues, reference will be made to previous statements. The following recommendations will be restricted to the single-breath technique of measuring the uptake of carbon monoxide in the lung, since this is the most common methodology in use around the world.

\section{Methods}

An application was submitted for a joint European Respiratory Society (ERS) and American Thoracic Society (ATS) task force to update the 2005 DLCO standards [4] with a particular view to systems using RGAs. The task force co-chairs were approved by the ERS and the ATS. Task force members were scientists and physicians with experience in international guidelines, clinical experience of routine lung function testing and specialist knowledge of gas transfer including research publications. Potential conflicts of interest were disclosed and vetted. The task force consisted of five members of the task force for the 2005 DLCO standards and four new members. A search using PubMed for literature published between 2000 and 2015 containing various terms related to diffusing capacity and transfer factor yielded 3637 citations. Task force members reviewed the abstracts and identified 113 as relevant to the project and a further 99 as potentially relevant. All manufacturers of pulmonary function equipment to measure DLCO were sent a survey requesting equipment specifications. Eight of 13 manufacturers responded. A survey of DLCO equipment specifications published on the manufacturers' websites was also conducted. Using the 2005 standards as a base document, revisions and additions were made on a consensus basis. The recommendations in this document represent the consensus of task force members in regard to the evidence available for various aspects of DLCO measurement (as cited in the document). Furthermore, it reflects the expert opinion of the task force members in areas in which peer-reviewed evidence was either not available or incomplete. The task force also identified areas and directions for future research and development where evidence is lacking.

\section{Determinants of carbon monoxide uptake}

The volume of carbon monoxide in the alveolar space is the product of the alveolar volume (VA) and the alveolar carbon monoxide fraction (FACO; i.e. the fractional concentration of carbon monoxide in the alveolar space). Thus, at a constant volume, the transfer of carbon monoxide from the lungs into the blood is $V \mathrm{~A} \cdot \Delta F \mathrm{ACO} / \Delta t$. Furthermore, in the absence of any carbon monoxide back-pressure in the blood, the transfer of carbon monoxide is equal to the product of the alveolar carbon monoxide tension ( $P$ ACO; i.e. the partial pressure of carbon monoxide) and the DLCO, which is the conductance of carbon monoxide from the inspired test gas in the alveolar space to binding with haemoglobin $(\mathrm{Hb})$ in the blood 
(i.e. flow $=$ pressure $\times$ conductance). The combination of these two formulae gives equation 1 , which can be manipulated to give equation 2 for the calculation of DLCO.

$$
\begin{aligned}
& V_{\mathrm{A}} \cdot \Delta F_{\mathrm{ACO}} / \Delta t=P_{\mathrm{ACO}} \cdot D_{\mathrm{LCO}} \\
& D_{\mathrm{LCO}}=V_{\mathrm{A}} \cdot \Delta F_{\mathrm{ACO}} / \Delta t / P_{\mathrm{ACO}}
\end{aligned}
$$

The ERS recommends expressing DLCO in SI units $\left(\mathrm{mmol} \cdot \mathrm{min}^{-1} \cdot \mathrm{kPa}^{-1}\right.$ ) while the ATS prefers traditional units $\left(\mathrm{mL} \cdot \mathrm{min}^{-1} \cdot \mathrm{mmHg}^{-1}\right)$ under standard temperature, pressure and dry conditions (STPD). Values in SI units can be multiplied by 2.987 to obtain values in traditional units.

The capacity of the lung to exchange gas across the alveolar-capillary interface is determined by its structural and functional properties [1,7-25]. The structural properties include the following: lung gas volume; the path length for diffusion in the gas phase; the thickness and area of the alveolar capillary membrane; any effects of airway closure; and the volume of $\mathrm{Hb}$ in capillaries supplying ventilated alveoli. The functional properties include the following: absolute levels of ventilation and perfusion; the uniformity of the distribution of ventilation relative to the distribution of perfusion; the composition of the alveolar gas; the diffusion characteristics of the membrane; the concentration and binding properties of $\mathrm{Hb}$ in the alveolar capillaries; and the carbon monoxide and oxygen tensions in the alveolar capillaries in that part of the pulmonary vascular bed which exchanges gas with the alveoli.

The process of carbon monoxide transfer from the environment to the pulmonary capillary blood includes six steps, as follows: 1) bulk-flow delivery of carbon monoxide to the airways and alveolar spaces; 2) mixing and diffusion of carbon monoxide in the alveolar ducts, air sacs and alveoli; 3) transfer of carbon monoxide across the gaseous to liquid interface of the alveolar membrane; 4) mixing and diffusion of carbon monoxide in the lung parenchyma and alveolar capillary plasma; 5) diffusion across the red-cell membrane and within the interior of the red blood cell; 6) chemical reaction with constituents of blood $\mathrm{Hb}$ [13-19].

The process of carbon monoxide uptake can be simplified into two transfer or conductance properties: 1) membrane conductivity $(D M)$, which reflects the diffusion properties of the alveolar capillary membrane; and 2) binding of carbon monoxide and $\mathrm{Hb}$. The latter can be represented as the product of the carbon monoxide-Hb chemical reaction rate $(\theta)$ and the volume of alveolar capillary blood $\left(V_{C}\right)$. Since these conductances are in series [17], these properties are related as shown in equation 3.

$$
1 / D_{\mathrm{LCO}}=1 / D_{\mathrm{M}}+1 / \theta V_{\mathrm{C}}
$$

A number of physiological changes can affect $D M$ or $\theta V C$ to influence DLCO. For example, as the lung inflates $D M$ increases (largely due to increasing alveolar surface area), while $V C$ effects are variable (due to differential stretching and flattening of alveolar and extra-alveolar capillaries) [13, 20-27]. The net effect of these changes is that DLCO tends to increase as the lung inflates but the change in DLCO is proportionally less than the change in $V \mathrm{~A}$ [22]. Exercise, the supine position and Müller manoeuvres (inspiratory efforts against a closed glottis) can all recruit and dilate alveolar capillaries, thereby increasing VC and DLCO [28-34]. Alveolar-capillary recruitment also occurs in the remaining lung tissue following surgical resection, since the cardiac output now flows through a smaller capillary network. This causes a less than expected loss of $V C$ for the amount of lung tissue removed. In contrast, Valsalva manoeuvres (expiratory efforts against a closed glottis) can reduce VC and thereby reduce DLCO [32].

The measurement of carbon monoxide uptake is also affected by the distribution of ventilation with respect to $D M$ or $\theta V C$ (i.e. carbon monoxide uptake can only be measured in lung units into which carbon monoxide was inspired and subsequently expired) $[18,19,35,36]$. This is particularly important in diseases such as emphysema, where the inhaled carbon monoxide may preferentially go to the better-ventilated regions of the lung and the subsequently measured carbon monoxide uptake will be determined primarily by the uptake properties of these regions. Under these conditions, the tracer gas dilution used to calculate $V \mathrm{~A}$ will also reflect primarily regional dilution and underestimate the lung volume as a whole. The resulting calculated DLCO value should thus be considered as primarily reflecting the gas-exchange properties of the better ventilated regions of the lung.

In addition to these physiological and distributional effects on DLCO, a number of pathological states can affect $D \mathrm{M}, \theta V \mathrm{C}$, or both and thereby affect DLCO $[8,9,37-46]$. Measurement of DLCO is used when any of these pathological processes are suspected or need to be ruled out. Moreover, measuring changes in DLCO over time in these processes is a useful way of following the course of the disease. 


\section{Gas analysers and general equipment \\ System design}

Descriptions of the apparatus and general instructions for performing the single-breath diffusing capacity manoeuvre are available elsewhere $[2,6,47-50]$. Equipment in clinical use varies widely in complexity but the basic principles are the same. All systems have a source of test gas, a method of measuring inspired and expired volume over time and a method of measuring carbon monoxide and tracer gas concentration. Classical discrete-sample gas-analyser DLCO systems usually display only volume over time but RGA DLCO systems also provide a continuous recording of carbon monoxide and tracer gas concentration during the entire test manoeuvre (figure 1).

\section{Equipment requirements}

The performance standards for DLCO equipment are summarised in table 1 .

\section{Flow and volume analysers}

Any error in measuring flow and subsequently calculating volume will produce a correspondingly equal error in DLCO. However, with continuing improvement in flow measurement technologies, improved accuracy is being achieved. The flow measurement accuracy over a range of -10 to $+10 \mathrm{~L} \cdot \mathrm{s}^{-1}$ must be within $\pm 2 \%$. For calibration with a 3 -L syringe, which has a specified maximum error of $\pm 0.5 \%$ (i.e. 2.985 to $3.015 \mathrm{~L}$ ), the calibration volume must be within $\pm 2.5 \%$ which is equivalent to an error tolerance of $\leqslant 75 \mathrm{~mL}$. The volume measurement accuracy must be maintained over the range of gas compositions and concentrations likely to be encountered during DLCO tests.

\section{Gas analysers}

For classical discrete sample calculations of DLCO, only the ratios of alveolar to inhaled carbon monoxide and tracer gas concentrations are needed. Thus, the analysers must primarily be able to produce an output for measured exhaled carbon monoxide and tracer gas that is a linear extrapolation between the inhaled (test gas) concentrations and zero (no carbon monoxide or tracer gas present in the analysers) [51, 52]. The measurement of carbon monoxide and tracer gas concentrations is also a static measurement when considering a classical discrete sample calculation of DLCO. Analyser response time is not an issue and the time of gas sample collection is measured separately. Gas concentration digital signal conditioning is not required to compensate for the response time when calculating DLCO using static measurements.

When nondispersive, infrared carbon monoxide RGAs began to be used to construct a virtual gas sample from flow and gas concentration data, rather than collecting a physical sample of exhaled gas, no specifications were mandated other than for the linearity of the gas analysers [5]. However, with RGAs there is both a lag time (due to the travel of the sampled gas through the sampling tube to the analyser chamber) and an analyser response time (the time to reach $90 \%$ of the actual measurement from the time the gas sample reaches the analyser) to be considered. As such, the gas concentration signal must be precisely shifted in time to align with the flow signal (figure 2).

\section{RGA response time}

The response time of the RGA will determine how accurately the analyser is able to track the true carbon monoxide and tracer gas concentrations. The most rapid changes in concentration occur at the start of test

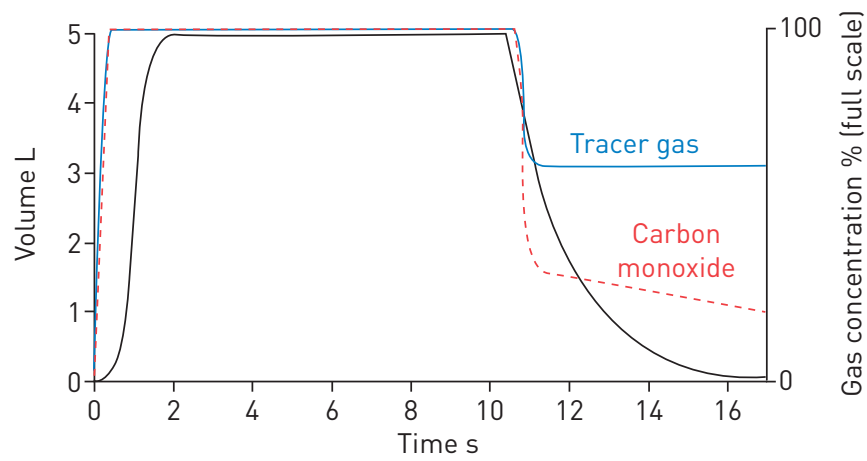

FIGURE 1 Diagram of lung volume and gas concentration during the single-breath manoeuvre to measure the uptake of carbon monoxide. Whereas classical DLCO systems only display the volume-time graph, rapid gas analyser (RGA) DLCo systems also display the carbon monoxide and tracer gas concentrations throughout the single-breath manoeuvre. Reproduced from [4]. 
TABLE 1 Equipment specifications and performance standards

DLco System

\section{Specification}

Required

$\leqslant 150 \mathrm{~ms}$

$\pm 1 \%$ of full scale

Within $\pm 1 \%$ of full scale

$\leqslant 10 \mathrm{ppm}$ error in [CO]

$\leqslant 10 \mathrm{ppm}$ over $30 \mathrm{~s}$

$\leqslant 0.5 \%$ of full scale over $30 \mathrm{~s}$

Within $\pm 2 \%$ over the range of

-10 to $+10 \mathrm{~L} \cdot \mathrm{S}^{-1}$

Within $\pm 75 \mathrm{~mL}$

Within $\pm 2.5 \%$

Volume accuracy (3-L syringe check)

Ability to perform a QA check (3-L syringe; ATP

mode; inhaling $\sim 2 \mathrm{~L}$ test gas)

Sample and store data with adequate resolution

Monitor and report end-expiratory tracer gas and carbon monoxide concentrations lalert operator if washout is incomplete)

Compensate for end-expiratory gas concentrations prior to test gas inhalation in the calculation of $V_{A}$ and $D$ Lco

Ensure proper alignment of gas concentration signals and the flow signal

Measure anatomic dead-space using the Fowler method (see figure 6)

Display a graph of gas concentration versus expired volume to confirm the point of dead-space washout and report the amount of manual adjustment if done (see figure 4)

Measure $V_{A}$ using all of the tracer gas data from the entire manoeuvre in the mass balance equation

Report the $D\left\llcorner c 0\right.$ adjusted for the change in $\mathrm{PAO}_{2}$ due to barometric pressure

Ability to input simulated digital test data and compute D.co, $V_{A}$, TLC, Vo

Report the $D$ Lco adjusted for the change in $\mathrm{PAO}_{2}$ due to $\mathrm{PACO}_{2}$, if the carbon dioxide concentration signal is available
Calculate total volume $\left(V_{A}\right)$ of $3 \pm 0.3 \mathrm{~L}$ and

$D \mathrm{LCO}$ of $<0.5 \mathrm{~mL} \cdot \mathrm{min}^{-1} \cdot \mathrm{mmHg}^{-1}$ or

$<0.166 \mathrm{mmol} \cdot \mathrm{min}^{-1} \cdot \mathrm{kPa}^{-1}$

Digitise at $\geqslant 100 \mathrm{~Hz}$

per channel with $\geqslant 14$ bit resolution

Implemented ${ }^{\#}$

Implemented

Implemented $\#$

Implemented ${ }^{\#}$

Implemented $^{\#}$

Implemented ${ }^{\#}$

Implemented ${ }^{\#}$
Digitise at $1000 \mathrm{~Hz}$

\section{Recommended}

Classical discrete sample systems

\section{Analyser specification}

Maximum nonlinearity

Accuracy

Interference from $5 \%$ carbon dioxide or $5 \%$ water vapour

Drift for carbon monoxide

Drift for tracer gas

Flow accuracy

Volume accuracy (3-L syringe check)

Ability to perform a QA check (3-L syringe; ATP mode; inhaling $\sim 2$ L test gas) $\pm 1 \%$ of full scale

Within $\pm 1 \%$ of full scale

$\leqslant 10 \mathrm{ppm}$ error in [CO]

$\leqslant 10 \mathrm{ppm}$ over $30 \mathrm{~s}$

$\leqslant 0.5 \%$ of full scale over $30 \mathrm{~s}$

Within $\pm 2 \%$ over the range of

-10 to $+10 \mathrm{~L} \cdot \mathrm{s}^{-1}$

Within $\pm 75 \mathrm{~mL}$

Calculate total volume $\left(V_{A}\right)$ of $3 \pm 0.3 \mathrm{~L}$

and $D \mathrm{LCO}$ of $<0.5 \mathrm{~mL} \cdot \mathrm{min}^{-1} \cdot \mathrm{mmHg}^{-1}$ or

$<0.166 \mathrm{mmol} \cdot \mathrm{min}^{-1} \cdot \mathrm{kPa}^{-1}$

DLCO: diffusing capacity of the lung for carbon monoxide; [CO]: carbon monoxide concentration; QA: quality assurance; ATP: ambient temperature, pressure and humidity; $V \mathrm{~A}$ : alveolar volume; $P_{\mathrm{AO}_{2}}$ : alveolar oxygen tension; $P_{\mathrm{ACO}_{2}}$ : alveolar carbon dioxide tension; TLC: total lung capacity; VD: dead-space volume. ${ }^{\#}$ : Implemented means that the manufacturer has implemented the designated functionality in the DLCo system.

gas inhalation and at the start of exhalation following the breath-hold. Even after the application of an appropriate time shift (see below) to correct for lag time and analyser response time, there will be a residual error in DLCO due to the finite response time. For every $100 \mathrm{~ms}$ increase in the $0-90 \%$ response 


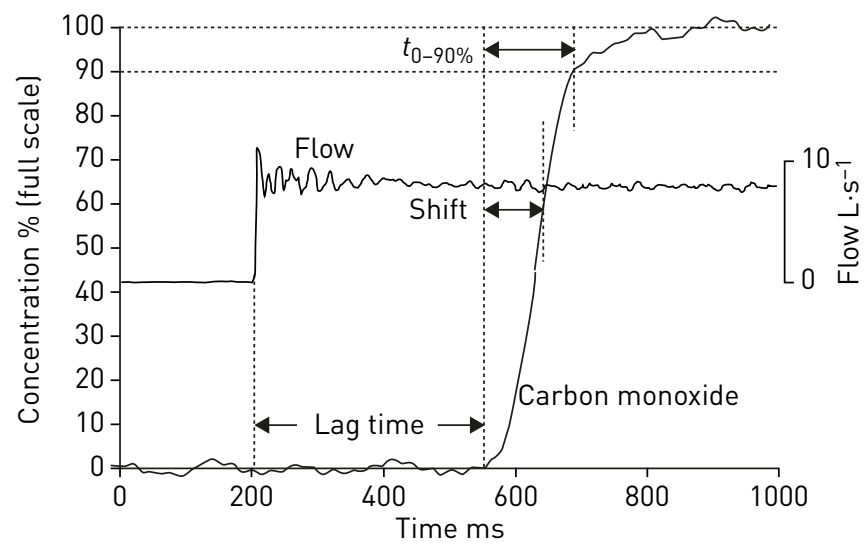

FIGURE 2 Lag and response times for carbon monoxide: the response time of the analyser was estimated by rapidly switching the gas being sampled from zero to full-scale carbon monoxide. The change in the flow signal shows the time at which the switch was made from medical air to test gas. The lag time, the $0-90 \%$ response time and the optimal shift are calculated from the resulting response curve.

time, the error in DLCO increases by about $0.7 \%$ [53]. Based on the above considerations, the $0-90 \%$ response time for RGAs used in DLCO systems must be $\leqslant 150 \mathrm{~ms}$.

Response time can be improved by reducing the volume of the analyser chamber and increasing the sample aspiration rate: however, such measures can cause a deterioration of the signal by creating more noise. The use of signal conditioning to simulate a more rapid analyser response may also introduce more noise and errors into the signal. Digital conditioning techniques should only be used to digitally enhance response time if they do not compromise signal quality and accuracy and serve to preserve or improve DLCO measurement accuracy.

\section{Linearity and accuracy}

The linearity of gas concentration signals is of primary importance in measuring DLCO since the ratios of the gas concentrations are considered in the classical calculations [50,52]. The error in DLCO measurement due to nonlinearity in these signals depends on the size of the lungs and the rate of uptake of carbon monoxide. A nonlinearity of $0.5 \%$ of full scale can cause errors ranging from $0.5 \%$ in a subject with a DLCO of $13.4 \mathrm{mmol} \cdot \mathrm{min}^{-1} \cdot \mathrm{kPa}^{-1}\left(40 \mathrm{~mL} \cdot \mathrm{min}^{-1} \cdot \mathrm{mmHg}^{-1}\right)$ to $1.7 \%$ in a subject with a DLCO of $3.35 \mathrm{mmol} \cdot \mathrm{min}^{-1} \cdot \mathrm{kPa}^{-1}\left(10 \mathrm{~mL} \cdot \mathrm{min}^{-1} \cdot \mathrm{mmHg}^{-1}\right)$ [53]. The manufacturer specification for analyser linearity is that any nonlinearity must not exceed $0.5 \%$ of full scale once zero and full scale values have been set. The accuracy of the gas analyser signal also becomes important when measuring the residual background alveolar carbon monoxide concentration and the washout of tracer gas from the previous DLCO manoeuvre. The output of the gas analyser must be accurate to within $\pm 1 \%$ of full scale.

\section{Interference and noise}

Nondispersive, infrared carbon monoxide analysers typically have some cross sensitivity to carbon dioxide and water vapour. Strategies to reduce and/or compensate for cross sensitivity are required such that the water vapour and carbon dioxide in exhaled gas (up to $5 \%$ each; i.e. water vapour pressure $\left(\mathrm{P}_{2} \mathrm{O}\right)$ $6.28 \mathrm{kPa} / 47 \mathrm{mmHg}$ ) contribute a less than $10 \mathrm{ppm}$ error in the measured carbon monoxide signal. Measuring the exhaled gas from the subject prior to the inhalation of test gas can also provide an offset due to carbon dioxide and water vapour measurements that can be used to adjust the concentration signal.

\section{Drift}

Gas analysers should have only minimal drift in zero and gain, such that output is stable over the test interval. Gas analyser drift must be $\leqslant 10 \mathrm{ppm}$ over $30 \mathrm{~s}$ for carbon monoxide and $\leqslant 0.5 \%$ of full scale over $30 \mathrm{~s}$ for tracer gas. It is recommended that manufacturers provide an optional test mode to display the measured gas concentrations so that stability can be confirmed. Any drift must be determined by comparing the carbon monoxide and tracer values measured in room air immediately prior to and immediately following the single-breath manoeuvre. The gas concentration signals used in the calculation of DLCO must be compensated for drift, assuming a linear change over the measurement interval.

\section{Aspiration flow}

Depending upon the design of the breathing circuit, the gas analyser sampling port and the gas analyser aspiration flow, gas may be entrained into the sampling line from room air or from the test gas when the 
exhaled flow decreases to near zero at the end of exhalation. Clearly, when the subject's exhaled flow drops below the aspiration flow, the sample will entrain other gas that is not part of the exhaled gas. DLCO instrument manufacturers are required to determine the lowest exhaled flow at which the gas sampling line will not entrain gas other than exhaled gas. This flow must be reported in the system specifications. In the analysis of the exhaled gas concentration data, measurements of gas concentration below the specified flow must not be included in either the determination of washout of tracer gas from a previous manoeuvre (see the section on interval between manoeuvres below) or the calculation of absolute end-expiratory lung volume ( $V$ ee) in equations 22 and 25 below.

\section{Digitisation}

In order for the digitised signal to accurately track the gas concentration signal and in order to provide adequate opportunity for signal processing for data alignment, the minimum signal sampling rate must be $\geqslant 100 \mathrm{~Hz}$ per channel: however, a rate of $1000 \mathrm{~Hz}$ is recommended. The analogue to digital converter resolution must be $\geqslant 14$ bits.

\section{Other equipment considerations}

Circuit resistance must be $<1.5 \mathrm{cmH}_{2} \mathrm{O} \cdot \mathrm{L}^{-1} \cdot \mathrm{s}^{-1}$ up to $6 \mathrm{~L} \cdot \mathrm{s}^{-1}$ flow. If a demand-flow regulator is used on a compressed test gas cylinder, the maximal inspiratory pressure required for $6 \mathrm{~L} \cdot \mathrm{s}^{-1}$ inspiratory flow through both the circuit and the valve must be $<9 \mathrm{cmH}_{2} \mathrm{O}$.

Equipment dead-space volume ( $V$ Dequip) for both inspired test gas and the alveolar sample must be known and their role in all data computation algorithms must be identified and documented. For adults, the $V$ Dequip including the breathing circuit proximal to the gas analyser sampling point, filter and mouthpiece must be $<200 \mathrm{~mL}$. Smaller dead-space volumes are recommended for paediatric applications and people with a vital capacity (VC) of less than $2 \mathrm{~L}$.

The system must be leak free; this is particularly important for DLCO systems that aspirate gas samples through the gas analyser at sub-atmospheric pressures. When samples are aspirated, leaks in tubing, fittings and other locations allow room air to be drawn into the gas circuit, thus diluting the sample and reducing the concentrations of carbon monoxide and tracer gases.

\section{Equipment calibration and quality control}

The considerations for equipment calibration and quality control are illustrated in table 2 . There are a number of regular procedures to apply, summarised as follows:

1) Flow and gas analysers must be zeroed prior to each manoeuvre. After each manoeuvre, a new zeroing procedure must be carried out to account for analyser drift during the previous test.

2) Each day, prior to testing, there must be a volume calibration check with a 3-L syringe [54]. The syringe should be discharged at least three times to give a range of flow rates varying between 0.5 and $12 \mathrm{~L} \cdot \mathrm{s}^{-1}$ (with 3 - $\mathrm{L}$ injection times of $\sim 6 \mathrm{~s}$ and $\sim 0.5 \mathrm{~s}$, respectively). The volume at each flow rate must meet an accuracy requirement of $\leqslant 2.5 \%$ error. For devices using disposable flow sensors, a new sensor from the supply used for patient tests must be tested each day. The calibration check may need to be repeated during the day if ambient conditions change. Newer systems monitor ambient conditions and make adjustments as necessary or produce a calibration alert when needed. Older systems may require a calibration check if room temperature changes by more than $3{ }^{\circ} \mathrm{C}$ or relative humidity changes by more than $15 \%$ (absolute). Operators should also perform a calibration check whenever they notice significant

\section{TABLE 2 Equipment calibration schedule}

Calibration technique

Frequency

Flow analyser zeroing

Gas analyser zeroing

Volume calibration check

Biologic control

Calibration syringe DLco check

Calibration syringe leak test

Linearity check (calibration syringe or simulator)
Before each test Before/after each test Daily

Weekly

Weekly

Monthly

Monthly

DLCO: diffusing capacity of the lung for carbon monoxide. 
discrepancies between the inspired volume (VI) and VC, or between VA and total lung capacity (TLC), which might suggest volume calibration problems.

3) Each week, or whenever problems are suspected, the following procedures must be followed. First, for those DLCO systems using a volume-type spirometer, a spirometer leak test should be performed according to the manufacturer's specifications. Secondly, a DLCO test should be performed with a calibrated 3-L syringe by attaching the syringe to the instrument in the normal patient test mode. The syringe should then be emptied, filled with $3 \mathrm{~L}$ of test gas and emptied into the mouthpiece after the $10 \mathrm{~s}$ breath-hold. The calculation of VA must be within $300 \mathrm{~mL}$ of $3 \mathrm{~L}$ times the ATPD to BTPS (body temperature, ambient pressure, saturated with water vapour conditions) correction factor, which is $310 / T_{A} \cdot P_{\mathrm{B}} /\left(P_{\mathrm{B}}-47\right)$, where $T_{\mathrm{A}}$ is the ambient temperature in degrees kelvin and $P \mathrm{~B}$ is the barometric pressure in $\mathrm{mmHg}$. It should be noted that a 3-L calibration syringe will have an additional dead-space which, depending on the connection to the mouthpiece, is typically $\sim 50 \mathrm{~mL}$ and must be considered in the $V$ A calculation. The absolute value of the calculated DLCO must be $<0.166 \mathrm{mmol} \cdot \mathrm{min}^{-1} \cdot \mathrm{kPa}^{-1}$ or $<0.5 \mathrm{~mL} \cdot \mathrm{min}^{-1} \cdot \mathrm{mmHg}^{-1}$. Thirdly, a test should be performed on a "standard subject" (biological control) or simulator [55]. Standard subjects are nonsmokers who have been found to have a consistently repeatable DLCO (e.g. healthy laboratory personnel). If the DLCO in a standard subject varies either by $>12 \%$ or by $>1 \mathrm{mmol} \cdot \mathrm{min}^{-1} \cdot \mathrm{kPa}^{-1}\left(>3 \mathrm{~mL} \cdot \mathrm{min}^{-1} \cdot \mathrm{mmHg}^{-1}\right)$ from the mean of previous values, the test must be repeated. A study of the long-term intersession variability of DLCO has found that biological control deviations either $>12 \%$ or $>3 \mathrm{~mL} \cdot \mathrm{min}^{-1} \cdot \mathrm{mmHg}^{-1}$ from the average of the first six tests indicate that the instrument is not within quality control limits and must be carefully evaluated before further patient testing [56]. For a digital system check of the DLCO calculation algorithm, standardised digital data for flow, volume and carbon monoxide and tracer gas concentration will be developed by the task force and made available with a sample rate of $1 \mathrm{kHz}$ as an $\mathrm{xml}$ or csv file. It is strongly recommended that manufacturers provide the ability to input data from such a file and generate test results to compare measured versus known DLCO and VA values. For systems failing the above testing, the DLCO system must be evaluated carefully for the possibility of leaks, nonlinear analyser function, and volume and time inaccuracy, etc. When sufficient data on a standard individual have been obtained, laboratories should establish their own outlier criteria to serve as indicators of potential problems with their DLCO systems. Manufacturers are encouraged to develop automated quality-control software to assist and enhance the utility of these steps.

4) Each month a leak test of the 3-L calibration syringe should be performed. If the calibration syringe does not have a volume scale on the shaft, mark $50 \mathrm{~mL}$ below full by measuring the excursion of the shaft from 0 to $3 \mathrm{~L}$ and marking it at a distance that is 0.017 of the full excursion. Fill the syringe and place a stopper at the syringe input. Push the syringe in to the $50 \mathrm{~mL}$ mark (which generates a pressure of about $17 \mathrm{cmH}_{2} \mathrm{O}$ ), hold for $10 \mathrm{~s}$ and release. If the syringe does not return to within $10 \mathrm{~mL}$ of the full position, it should be sent for repair. The procedure is then repeated starting with the syringe at $50 \mathrm{~mL}$ below full, applying the stopper and pulling the syringe to the full position.

5) Each month, gas-analyser linearity should be assessed. A straightforward approach is to measure known serial dilutions of the test gas [57], or to measure the concentration of a separate high-precision test gas having a certificate of analysis. Manufacturers must be encouraged to automate this function. For systems with independent measurement of carbon monoxide and tracer gas, the analyser linearity may also be assessed by comparing the ratio of carbon monoxide and tracer gas concentration to arbitrary dilutions of test gas with room air. A third type of calibration syringe test, which differs from the volume check in point two and the DLCO check in point three by using the 3-L syringe in ambient temperature, pressure and humidity (ATP) mode, may also reveal problems with analyser linearity. With approximately $1 \mathrm{~L}$ of air in the syringe, the test begins by filling the remaining volume with test gas. Following a $10 \mathrm{~s}$ "breath-hold" the syringe is then emptied. The calculation of VA must be within $300 \mathrm{~mL}$ of $3 \mathrm{~L}$ with the syringe dead-space being used for the anatomic dead-space in the VA calculation. The absolute value of DLCO must be $<0.166 \mathrm{mmol} \cdot \mathrm{min}^{-1} \cdot \mathrm{kPa}^{-1}$ or $<0.5 \mathrm{~mL} \cdot \mathrm{min}^{-1} \cdot \mathrm{mmHg}^{-1}$. A review of quality control data for four different DLCO systems between 2006 and 2015 using this procedure found only four outlier points where $\mid D$ LCO $\mid$ was $>0.13 \mathrm{mmol} \cdot \mathrm{min}^{-1} \cdot \mathrm{kPa}^{-1}\left(>0.4 \mathrm{~mL} \cdot \mathrm{min}^{-1} \cdot \mathrm{mmHg}{ }^{-1}\right)$. The same data showed that $V A$ was consistently within $3 \pm 0.3 \mathrm{~L}$ for the four systems (unpublished data from B.R. Thompson). Gas mixing in the syringe can be improved by using low flow rates and extending the breath-hold time. The effects of incomplete mixing in the syringe can be minimised by using a larger sample volume. In the absence of a DLCO simulator and high-precision test gases, system checks must be performed using a 3-L calibrating syringe in ATP mode. Manufacturers must provide this test option, which will be the same as the usual testing procedure for a patient, with the exception that VA will be reported in ATP rather than BTPS.

6) A record of equipment checks and standard subject tests should be dated and kept in a laboratory log book or digital file folder. Manufacturers are encouraged to provide software and test equipment options for quality control measurement and quality control data management. In addition, manufacturers may provide equipment-specific, quality-control measures in addition to the foregoing points. If water vapour 
permeable tubing is used to either remove water vapour or equilibrate water vapour with room air, such tubing must be replaced according to manufacturer recommendations to ensure that it is functioning properly. Chemical gas analyser cells will have a replacement schedule. Manufacturers may also have preventative maintenance schedules for various other system components (e.g. balloon valves) which will require testing and replacement as necessary.

\section{Quality control for RGA systems}

Modern DLCO systems are completely integrated and do not use stand-alone gas analysers that can be tested separately. Specifications for manufacturers are required to facilitate a uniform testing and calibration strategy across all systems. Quality-control requirements include analogue testing with devices such as a simulator [58], the option to operate in full ATP mode and a digital calibration option to verify the computational algorithms. The digital calibration option should use simulated flow, carbon monoxide concentration and tracer gas concentration data from standardised manoeuvres with a known DLCO.

\section{Infection control}

The major goal of infection control is to prevent the transmission of infection to patients and staff during pulmonary function testing. The recommendations in the ATS/ERS documents for spirometry and general considerations for pulmonary function testing also apply to DLCO equipment and procedures [59-61].

\section{Standardisation issues in the single-breath testing technique}

The single-breath determination of DLCO involves measuring the uptake of carbon monoxide from the lung over a breath-holding period. To minimise variability as much as possible, the following specifications for the standardisation of testing techniques are provided.

\section{Patient condition}

Factors that affect $V_{C}$ (e.g. exercise, body position, $\mathrm{Hb}$ affinity for carbon monoxide, alveolar oxygen tension $\left(\mathrm{PAO}_{2}\right)$, and level of carboxyhaemoglobin $\left.(\mathrm{COHb})\right)$ must be standardised. If clinically acceptable, the subject should not breathe supplemental oxygen for $\geqslant 10 \mathrm{~min}$ prior to a DLCO manoeuvre. In addition, when using exercise or the supine position to assess the ability of the lung to increase gas transfer [18, 2831], the level of exercise and/or the duration of the supine position must be noted. Before beginning the test, the manoeuvres must be demonstrated and the subject carefully instructed. Furthermore, the subject must be seated comfortably throughout the test procedure, which must be performed at a stable, comfortable temperature within the manufacturer's equipment specifications.

COHb produces an acute, reversible decrease in DLCO [62-66], largely due to its effects on carbon monoxide back-pressure and the "anaemia effect" from decreased $\mathrm{Hb}$ binding sites for test gas carbon monoxide. As cigarette smoking is the most common source of $\mathrm{COHb}$, subjects must be asked to refrain from smoking or other sources of carbon monoxide exposure on the day of the test. The time of the last cigarette smoked must be recorded and noted for the interpretation. A correction for carbon monoxide back-pressure must be made for recent or heavy cigarette smoking (see the section on adjustment for $\mathrm{COHb}$ concentration and carbon monoxide back-pressure below). Air pollution may also result in higher $\mathrm{COHb}$ levels and exposure to high levels of air pollution should be noted.

\section{Inspiratory manoeuvres}

Once the mouthpiece and nose clip are in place, tidal breathing must be carried out for a sufficient time to assure that the subject is comfortable with the mouthpiece and that the nose clips and mouthpiece are used appropriately with no leaks. The DLCO manoeuvre begins with unforced exhalation to residual volume (RV). In obstructive lung disease, where exhalation to RV may require a prolonged period, a reasonable recommendation is that this portion of the manoeuvre must be limited to $<12 \mathrm{~s}$. Exhalation times of up to $12 \mathrm{~s}$ will allow most patients with airflow obstruction to exhale sufficiently such that they can achieve a maximal VC for the subsequent inhalation of test gas. Submaximal inhalation occurs most frequently in patients with airflow obstruction who are not given adequate time to exhale prior to the inhalation of test gas.

At RV, the subject's mouthpiece is connected to a source of test gas, and the subject inhales rapidly to TLC.

A submaximal inspired volume of test gas (i.e. less than the known VC) can affect carbon monoxide uptake depending upon whether it is a result of an initial suboptimal exhalation to RV (manoeuvre performed at TLC) or whether it is due to a suboptimal inhalation from RV (manoeuvre performed below TLC) [22-25]. In the former case, the calculated VA and DLCO will accurately reflect lung volume and the carbon monoxide uptake properties of the lung at TLC. In the latter case, the VA will be reduced and DLCO measurement will be affected. 
Due to these effects, it is important that the inspired volume of test gas, VI, be as close to the known VC as possible. Data from a large patient population have shown that the VI during DLCO measurement averages $\sim 90 \%$ of the VC [22]. Since the introduction of the 2005 guidelines and subsequent implementation of quality-control checks by equipment manufacturers, there has been an improvement in test quality such that $90 \%$ of the largest known VC as the lower limit of acceptability for VI has been shown to be attainable [67]. Furthermore, as noted above, VI will be improved by allowing up to $12 \mathrm{~s}$ for exhalation prior to inhalation of test gas. VI must be at least $90 \%$ of the largest VC in the same pulmonary function testing session. However, a manoeuvre may be deemed to be acceptable if $V_{\mathrm{I}}$ is within $85 \%$ of the largest VC and the VA is within $200 \mathrm{~mL}$ or $5 \%$ (whichever is greater) of the highest VA among acceptable DLCO manoeuvres.

The inspiration must be rapid, since the DLCO calculations assume instantaneous lung filling [27, 68-74]. Slower lung filling decreases the amount of time the lung is at full inspiration with a consequent reduction in carbon monoxide uptake. Although various sample timing techniques address the issue of lung filling and emptying time, inspiration of test gas should be sufficiently rapid such that that $85 \%$ of $V$ I must be inspired in $<4.0$ s. If longer inspiratory times are needed to inspire $85 \%$ of $V \mathrm{I}$, this must be noted on the test report.

\section{Breath-hold and expiratory manoeuvres}

During the breath-hold, both the Valsalva and Müller manoeuvres (expiratory or inspiratory efforts against a closed glottis, respectively) can affect DLCO calculation by decreasing or increasing thoracic blood volume, respectively, resulting in a corresponding decrease or increase in DLCO, respectively, for each manoeuvre [32, 75, 76]. The intrapulmonary pressure during the breath-hold should thus be near atmospheric and this is best accomplished by having the subject voluntarily maintain full inspiration using only the minimal necessary effort. The breath-hold time must be $10 \pm 2 \mathrm{~s}$, a target easily achieved in the vast majority of subjects [77].

As with inspiration, the DLCO calculation assumes instantaneous lung emptying [27, 68-72]. Although various sample timing techniques address the fact that emptying is not instantaneous, it is still reasonable to expect that the expiratory manoeuvre must be smooth, unforced and without hesitation or interruption.

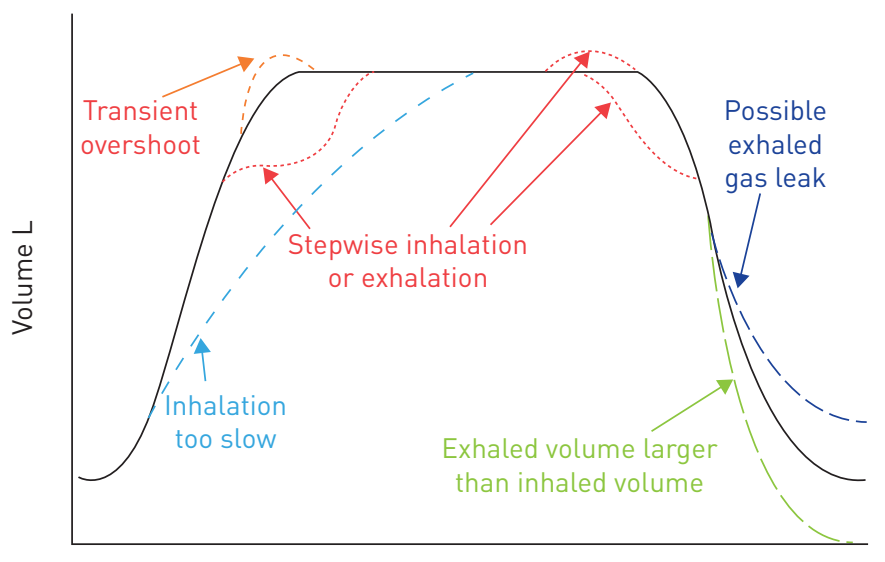

Time s

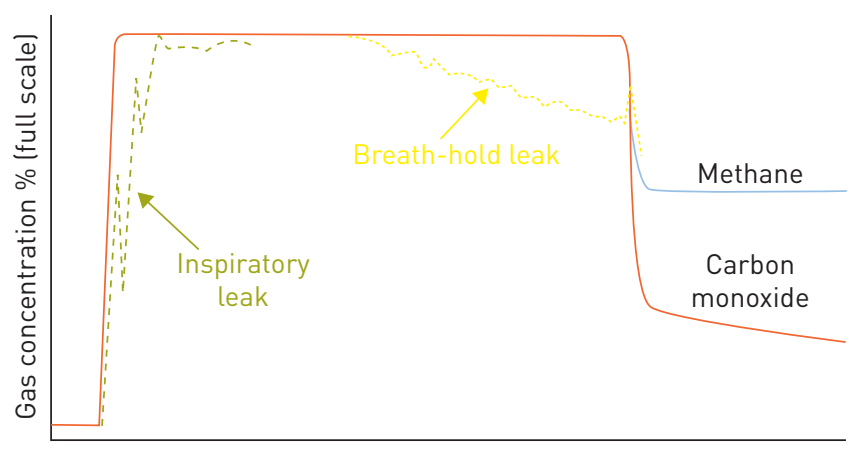

Time s

FIGURE 3 Potential problems with the breathing manoeuvre for single-breath diffusing capacity of the lung for carbon monoxide that can lead to measurement errors. Reproduced from [4]. 
For classical systems, the exhalation time for washout and discrete sample collection should not exceed $4 \mathrm{~s}$. In subjects who require a longer expiratory time to provide an appropriate alveolar gas sample, the expiratory time must be noted in the test report. For RGA systems, exhalation should continue to RV, with a maximum exhalation time of $12 \mathrm{~s}$, which provides improved measurement of $V \mathrm{~A}$ as noted in the data analysis for RGA systems section below. The results of common errors that can occur during the inspiration, breath-hold and expiration manoeuvres are illustrated in figure 3.

\section{Washout and sample collection manoeuvres}

DLCO calculations (see the calculations section below) are performed by analysis of discrete alveolar gas samples containing carbon monoxide and tracer gas. During expiration, a volume of gas must be expired to clear the total anatomical and equipment dead-space volume $(V D)$ and then discarded before the alveolar sample is collected (figure 1). Collecting an alveolar gas sample before the point of dead-space washout will underestimate DLCO, while delaying sample collection beyond the point of dead-space washout will overestimate DLCO $[68,72]$.

\section{Washout and sample collection in classical systems}

The washout volume must be $0.75-1.0 \mathrm{~L}$ (BTPS). If the patient's VC is $<2.00 \mathrm{~L}$, the washout volume may be reduced to $0.50 \mathrm{~L}$. The discrete-sample gas volume $(V s)$ is the volume of gas collected following the breath-hold and used to analyse alveolar carbon monoxide and tracer gas concentrations. Vs collection time will affect the measurement of breath-hold time (see below). For discrete sample systems that require larger sample volumes, a VS of $0.5-1 \mathrm{~L}$ should be collected for analysis. In patients with a VC $<1 \mathrm{~L}$, a Vs $<0.5 \mathrm{~L}$ may be used if it can be confirmed that the dead-space has been cleared.

\section{Washout and sample collection in RGA systems}

The time point for dead-space washout can be determined from the expired tracer gas concentration data using an objective algorithm. The beginning of the alveolar plateau can be located by determining the
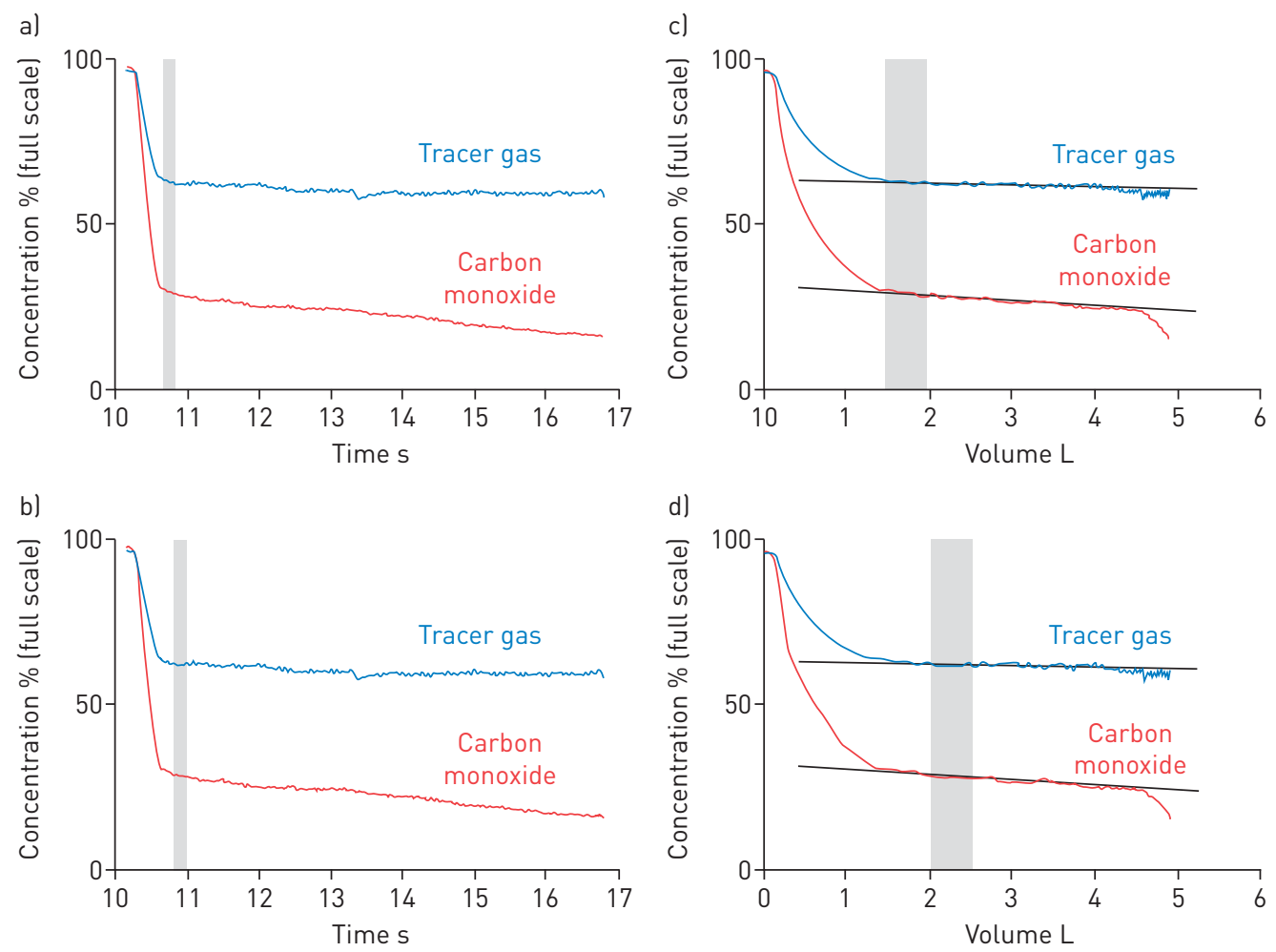

FIGURE 4 Comparison of gas concentration plotted as a function of time (a and b) or volume (c and d) for carbon monoxide and tracer gas. The shaded bar shows the collection of a $500-\mathrm{mL}$ sample of exhaled gas. The upper panels ( $\mathrm{a}$ and $\mathrm{c}$ ) show sample collection as selected by computer algorithm (based on gas concentration and lung volume). The lower panels ( $b$ and d) show sample collection after manual adjustment by an operator using the concentration versus time plot. Operators tend to be more conservative and may over-shift the sample. When gas concentration is plotted against time, the shift does not appear to be significant; however, when gas concentration is plotted against volume, the degree of shift becomes more apparent. 
breakpoint of each phase of the washout on a plot of concentration versus volume and adding a proportion of the dead-space volume measured by the Fowlen technique [78] to the phase II to III breakpoint [79]. Such an approach can be automated; however, for visual verification of the point of dead-space washout, the tracer gas concentration must be displayed as a function of volume, since verifying the point of dead-space washout using the concentration versus time curve can be deceptive due to the relatively high flow at the beginning of exhalation. This is illustrated in figure 4 . If the sample collection point is changed by the operator, it must be recorded in the database and on the report.

With RGA systems, the concentrations of carbon monoxide and tracer gas in a virtual alveolar gas sample are calculated for use in measuring DLCO. The gas concentrations in a virtual sample, that would have been observed in a sample of a given volume had it been collected at a given point during exhalation, are calculated from the flow and gas concentration data. A virtual 200-mL sample analysed by the method of JONES and MEADE [72] has been found to be robust [68]. However, these systems are capable of simulating much smaller gas samples and JONES and MEADE [72] used 85-mL gas samples in the development of their method. Smaller virtual samples will be more affected by noise in the expired carbon monoxide concentration signal. Virtual alveolar gas sample volumes of $85 \mathrm{~mL}$ to $500 \mathrm{~mL}$ may be used.

\section{Inspired gas composition}

The test gas used to calculate DLCO should contain very close to $0.3 \%$ carbon monoxide, $21 \%$ oxygen, a tracer gas and a balance of nitrogen. The tracer gas must be relatively insoluble and relatively chemically and biologically inert. Since the tracer gas is used to determine the initial alveolar carbon monoxide concentration, as well as the VA from which carbon monoxide uptake is occurring, its gaseous diffusivity should be similar to carbon monoxide and it should not interfere with the measurement of carbon monoxide concentration. The tracer gas should also not ordinarily be present in alveolar gas or else be present at a known, fixed concentration (e.g. argon).

Commonly used tracer gases include helium and methane. Helium meets most of the previous criteria; however, its gaseous diffusivity is considerably higher than that of carbon monoxide. Methane is commonly used for RGA systems; its gaseous diffusivity is closer to carbon monoxide but it has a slightly higher liquid solubility than helium. A recent study has found no clinical difference in DLCO using either helium or methane in normal subjects or patients with COPD [80].

As noted above, the inspired carbon monoxide concentration should be close to $0.3 \%$; however, as ratios are more important than absolute values, exact concentrations are not critical. The assumption in calculating carbon monoxide uptake is that capillary blood does not contain carbon monoxide. Thus, corrections are needed in patients who have significant $\mathrm{COHb}$ (see the section on adjustment for $\mathrm{COHb}$ concentration and carbon monoxide back-pressure below). There are two considerations influencing the rationale for recommending an inspiratory oxygen fraction $\left(\mathrm{FIO}_{2}\right)$ of $21 \%$ in the test gas for routine DLCO testing. First, the majority of studies developing reference values for DLCO, which are based on the 2005 standards [4], use an $\mathrm{FIO}_{2}$ of $21 \%$ (see the section on reference values below). Secondly, the $\mathrm{PAO}_{2}$ following a maximal inhalation will depend on the dead-space volume and the ratio of $V$ I to $V$ A for any given value of $\mathrm{FIO}_{2}$ in the test gas. Hence, if reducing $\mathrm{FIO}_{2}$ in the test gas is intended to simulate tidal breathing conditions (i.e. a $\mathrm{PAO}_{2}$ of $100 \mathrm{mmHg}$ or $13 \mathrm{kPa}$ ), it may not do so in all subjects.

Although not performed routinely, the measurement of DLCO at several different levels of $\mathrm{PAO}_{2}$ allows the two components of DLCO ( $D \mathrm{M}$ and $\theta V \mathrm{C})$ to be distinguished. This is accomplished by using the Roughton-Forster relationship noted previously (equation 3) and varying $\theta$ by altering $P_{A O}$. Subsequently, $1 / D$ LCO is plotted against $1 / \theta$ at the different $P_{A O}$ levels. The slope of this relationship is $1 / V C$ and the intercept is $1 / D \mathrm{M}$. While there are differences in the proposed value of $\theta$, it is beyond the scope of this report to make recommendations for the value of $\theta$ to be used.

\section{Manoeuvre intervals \\ Manoeuvre intervals in classical systems}

The 2005 ERS/ATS recommendations state that at least 4 min must be allowed between manoeuvres to allow for adequate elimination of test gas from the lungs. The subject should remain seated during this interval. In patients with airflow obstruction, a longer period (e.g. $10 \mathrm{~min}$ ) should be considered. Several deep inspirations during this period may help to clear test gases more effectively.

Manoeuvre intervals in RGA systems

Exhaled gas can be monitored as soon as the subject begins breathing through the mouthpiece prior to the inhalation of test gas. If a previous manoeuvre was conducted, the information collected on end-expiratory tracer gas levels will indicate whether or not washout is complete, which may occur in less than 4 min in some subjects. For complete washout, the tracer gas level at end-exhalation must be $\leqslant 2 \%$ of the tracer gas 
concentration in the test gas. Occasionally, if a subject has not reached this level of washout after 5 min, the operator may have the option of continuing with the next manoeuvre. However, in either event, the end-expiratory tracer gas concentration must be reported and used to adjust the tracer gas concentration data used in the determination of $V A$ at the beginning of breath-holding.

The carbon monoxide concentration measured in exhaled gas prior to inhaling test gas can be used for three important purposes [53]: 1) to adjust DLCO calculations for the back-pressure of carbon monoxide, both the ambient level and the increase that occurs with multiple DLCO manoeuvres; 2) to estimate the $\mathrm{COHb}$ concentration and adjust the DLCO calculation accordingly; and 3) to compensate for any residual effects of water vapour and carbon dioxide on the carbon monoxide analysers.

\section{Miscellaneous factors}

There may be a diurnal variation in DLCO, since one study has found that DLCO falls $1.2-2.2 \%$ per hour throughout the day [81]. The reason for this change is not clear and is not explained by carbon monoxide back-pressure or changes in $V \mathrm{~A}, V \mathrm{I}$, or breath-hold time. One explanation is a combination of changes in carbon monoxide back-pressure and diurnal variation in $\mathrm{Hb}$ concentration [82]. A $13 \%$ change in DLCO during the menstrual cycle has been reported [83]. The highest value is observed just before the menses and the lowest is observed on the third day of menses; however, it is not clear if this is simply a Hb effect or whether it reflects other physiological processes (e.g. hormonal changes on pulmonary vascular tone). Ingestion of ethanol has been reported to decrease DLCO $[84,85]$. The mechanisms involved are not clear, although it is known that some fuel-cell carbon monoxide analysers are sensitive to exhaled ethanol and ketones.

\section{Pulmonary function test sequence}

DLCO manoeuvres are frequently conducted immediately following the administration of $400 \mu \mathrm{g}$ of salbutamol in the interval between pre- and post-bronchodilator spirometry testing [60]. While an older study in obstructive lung disease subjects found that DLCO may increase by up to $6 \%$ after administration of a bronchodilator [86], a newer study has found that the administration of $400 \mu \mathrm{g}$ of salbutamol has no significant effect on DLCO in normal control subjects or in patients with either reversible on non-reversible airflow obstruction [87]. A further study has found no significant salbutamol effect on DLCO in COPD patients at doses of less than $1000 \mu \mathrm{g}$ [88]. Therefore, there is no recommendation against use of a bronchodilator prior to DLCO tests.

Spirometry is a form of exercise [59], which could conceivably impact on DLCO values; however, no studies were found which support a recommendation for a rest interval following spirometry. If the order of testing includes measuring absolute lung volumes using nitrogen washout, during which $100 \%$ oxygen is inspired [89] prior to DLCO manoeuvres, ample time is required for alveolar oxygen levels to return to normal. For nitrogen to wash back in to normal levels, allow a rest interval equal to twice the time required for the nitrogen washout test to be completed [90]. It is recommended that DLCO measurements be made before any multi-breath nitrogen washout tests.

\section{Calculations}

\section{Calculating diffusing capacity}

Converting equation 2 to calculus notation and using $P A C O=F A C O \cdot\left(P B-P \mathrm{H}_{2} \mathrm{O}\right)$, where $F$ ACO is the alveolar carbon monoxide fraction in the dry gas, $P \mathrm{~B}$ is the barometric pressure and $\mathrm{PH}_{2} \mathrm{O}$ is the water vapour pressure, gives equation 4 as shown below.

$$
\frac{d\left(V_{\mathrm{A}} \cdot F_{\mathrm{ACO}}\right)}{d t}=D_{\mathrm{LCO}} \cdot F_{\mathrm{ACO}} \cdot\left(P_{\mathrm{B}}-P_{\mathrm{H}_{2} \mathrm{O}}\right)
$$

Assuming a constant volume and that the pulmonary capillary carbon monoxide tension is near zero, solving for DLCO gives equation 5, where FACO,0 and FACO,t are the fractional concentrations of carbon monoxide in the alveolar volume at time 0 and time $t$, respectively. The rate of gas uptake is expressed in $\mathrm{mL}(\mathrm{STPD}) \cdot \mathrm{min}^{-1}$ and the transfer gradient (the difference between the alveolar and pulmonary capillary pressures) in $\mathrm{mmHg}$. Therefore, DLCO has traditional units of $\mathrm{mL}(\mathrm{STPD}) \cdot \mathrm{min}^{-1} \cdot \mathrm{mmHg}^{-1}$ and SI units of $\mathrm{mmol}(\mathrm{STPD}) \cdot \mathrm{min}^{-1} \cdot \mathrm{kPa}^{-1}$.

$$
D_{\mathrm{LCO}}=\frac{V_{\mathrm{A}}}{t \cdot\left(P_{\mathrm{B}}-P_{\mathrm{H}_{2} \mathrm{O}}\right)} \cdot \ln \left(\frac{F_{\mathrm{ACO}, 0}}{F_{\mathrm{ACO}, \mathrm{t}}}\right)
$$

The single-breath DLCO technique assumes that both carbon monoxide and the tracer gas are diluted equally on inspiration. Thus, the initial alveolar concentration of carbon monoxide at the theoretical start 
of breath-holding $(F \mathrm{ACO}, 0)$ can be calculated by knowing the inspired tracer gas fraction $(F \mathrm{Tr})$ and the alveolar tracer gas fraction (FATr). In this case, if FICO is the carbon monoxide fraction in the inspired test gas, we can generate equation 6 .

$$
F_{\mathrm{ACO}, 0}=F_{\mathrm{ICO}} \cdot \frac{F_{\mathrm{ATr}}}{F_{\mathrm{ITr}}}
$$

Tracer gas dilution is also used to determine the effective VA. If we solve for DLCO we can generate equation 7, where VA is reported in L (BTPS) and $t \mathrm{BH}$, the breath-hold time, is reported in seconds.

$$
D_{\mathrm{LCO}}=\frac{V_{\mathrm{A}}}{t_{\mathrm{BH}} \cdot\left(P_{\mathrm{B}}-P_{\mathrm{H}_{2} \mathrm{O}}\right)} \cdot \ln \left(\frac{F_{\mathrm{ICO}}}{F_{\mathrm{ACO}}} \cdot \frac{F_{\mathrm{ATr}}}{F_{\mathrm{ITr}}}\right)
$$

If we convert $V A$ to STPD conditions we obtain equation 8 for traditional units of DLCO $\left(V \mathrm{~A} \mathrm{~mL}(\mathrm{STPD}) \cdot \mathrm{min}^{-1} \cdot \mathrm{mmHg}^{-1}\right)$. The factor of 60000 arises from the change to the traditional units $(60 \mathrm{~s}$ to $1 \mathrm{~min}$ and $1 \mathrm{~L}$ to $1000 \mathrm{~mL}$ ).

$$
D_{\mathrm{LCO}}=\frac{V_{\mathrm{ASTPD}}}{t_{\mathrm{BH}} \cdot\left(P_{\mathrm{B}}-47\right)} \cdot \ln \left(\frac{F_{\mathrm{ICO}}}{F_{\mathrm{ACO}}} \cdot \frac{F_{\mathrm{ATr}}}{F_{\mathrm{ITr}}}\right) \cdot 60000
$$

If we then convert to SI units we obtain equation 9 (units of TLCO: $\mathrm{mmol} \cdot \mathrm{min}^{-1} \cdot \mathrm{kPa}^{-1}$ ), where the factor of 22.4 arises from the conversion of $\mathrm{mL}(\mathrm{STPD})$ to $\mathrm{mmol}$.

$$
T_{\mathrm{LCO}}=\frac{V_{\mathrm{ASTPD}}}{t_{\mathrm{BH}} \cdot\left(P_{\mathrm{B}}-6.28\right)} \cdot \ln \left(\frac{F_{\mathrm{ICO}}}{F_{\mathrm{ACO}}} \cdot \frac{F_{\mathrm{ATr}}}{F_{\mathrm{ITr}}}\right) \cdot 60000 / 22.4
$$

\section{Calculating breath-hold time}

The breath-hold time, or time of transfer during which carbon monoxide changes from its initial to its final concentration $(t \mathrm{BH})$, is part of the denominator in the DLCO equation (equation 7$)$. As noted previously, the single-breath measurement of carbon monoxide uptake assumes an instantaneous lung filling and emptying process. However, both inspiration and expiration require up to several seconds, and these periods of changing gas volume in the lung must be accounted for in the calculations. For purposes of standardisation, the method of Jones and MEADE (figure 5) [72] is recommended, since it has the theoretical appeal of empirically accounting for the effects of inspiratory and expiratory time. This method has also been shown to adequately address inspiratory flows as low as $1 \mathrm{~L} \cdot \mathrm{s}^{-1}$, breath-hold times as short as $5 \mathrm{~s}$ and expiratory flows as low as $0.5 \mathrm{~L} \cdot \mathrm{s}^{-1}$ in normal subjects [68] when using an RGA system that

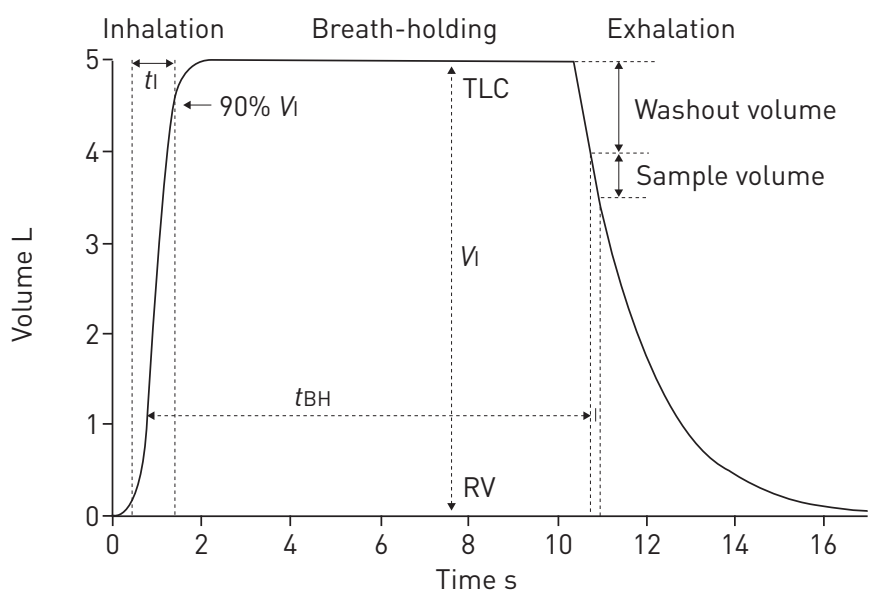

FIGURE 5 Schematic illustration of measuring breath-hold time for the single-breath diffusing capacity of the lung for carbon monoxide. The JoNES and MEADE [72] breath-hold time includes 0.7 of inspiratory time and half of sample time. $V_{l}$ : inspired volume; $t$ : time of inspiration (defined from the back-extrapolated time 0 to the time that $90 \%$ of the $V$ I has been inhaled); $t \mathrm{BH}$ : breath-hold time; TLC: total lung capacity; RV: residual volume. Reproduced from [4]. 
measures the dead-space and calculates $V A$ using the tracer gas concentration data from the entire manoeuvre. With the approach taken by JONES and MEADE [72], breath-hold time equals the time starting from 0.3 of the inspiratory time $(t \mathrm{I})$ to the middle of the sample collection time. As in spirometry, the back-extrapolation technique must be used to establish time zero $[2,59]$. The time when $90 \%$ of the VI has been inspired is a reasonable end-point for defining inspiratory time (figure 5).

\section{Calculating the alveolar volume \\ Alveolar volume in classical systems}

$V$ A represents an estimate of lung gas volume into which carbon monoxide is distributed and then transferred across the alveolar capillary membrane $[1,6]$ and is thus critical in the measurement of DLCO. Classical DLCo equipment collects an actual sample of exhaled gas for analysis and determination of the carbon monoxide and tracer gas concentrations. Since there is only one measurement, the alveolar volume is calculated from the same sample that is used for analysis of carbon monoxide uptake [2]. As noted elsewhere, JONES and MEADE [72] have shown that the sample has to be small $(85 \mathrm{~mL})$ to reduce errors in DLCO determination. The calculation of $V A$ requires an assumption that the alveolar gas is completely mixed at the maximal lung volume and that a small sample of exhaled gas will presumably be representative of the entire lung. In normal subjects this assumption is reasonable and has little effect on the measurement of $V$ A. However, in patients whose lung disease results in a heterogeneous distribution of ventilation, the size and timing of the sample have a major effect on the measurement of $V \mathrm{~A}$. For classical systems, VA is determined from values for VI, FITr and FATr (measured in the discrete-sample gas volume, $V S$ ). Since the amount of tracer gas in the lung (alveolar plus dead-space) equals the amount of inspired tracer gas and given that the dead-space tracer gas fraction is the same as the inspired fraction, we can generate equations 10 and 11 .

$$
\begin{gathered}
V_{\mathrm{I}} \cdot F_{\mathrm{ITr}}=V_{\mathrm{A}} \cdot F_{\mathrm{ATr}}+V_{\mathrm{D}} \cdot F_{\mathrm{ITr}} \\
V_{\mathrm{A}}=\left(V_{\mathrm{I}}-V_{\mathrm{D}}\right) \cdot F_{\mathrm{ITr}} / F_{\mathrm{ATr}}
\end{gathered}
$$

$V A$ is reported under BTPS conditions and then converted to STPD conditions to calculate DLCO, as in equations 8 and 9. The inspired volume $\left(V_{\mathrm{I}}\right)$ is the measured volume of inhaled dry gas and is thus considered to be under ambient temperature $(T)$, ambient pressure $(P \mathrm{~B})$, dry $(\mathrm{ATPD})$ conditions. The conversion to body temperature, ambient pressure, saturated with water vapour (BTPS) and standard temperature, pressure, dry (STPD) conditions may require conversion factors to compensate for the diluting or concentrating effects of adding or removing water vapour or carbon dioxide at the gas sampling site. Several examples of $V A$ calculations using such conversion factors are given below.

Where water vapour is removed from the sampled gas and carbon dioxide does not interfere with the analysers we can use equations 12 and 13 as follows, where VABTPS is the alveolar volume under BTPS conditions and VIATPD is the inspired volume under ATPD conditions.

$$
\begin{gathered}
V_{\text {ABTPS }}=\left(V_{\text {IATPD }}-V_{\text {Dequip }}-V_{\text {Danat }}\right) \cdot \frac{F_{\text {ITr }}}{F_{\text {ATr }}} \cdot \frac{P_{\mathrm{B}}}{\left(P_{\mathrm{B}}-47\right)} \cdot \frac{310}{(273+T)} \\
V_{\text {ASTPD }}=\left(V_{\text {IATPD }}-V_{\text {Dequip }}-V_{\text {Danat }}\right) \cdot \frac{F_{\text {ITr }}}{F_{\text {ATr }}} \cdot \frac{P_{\mathrm{B}}}{760} \cdot \frac{273}{(273+T)}
\end{gathered}
$$

Where water vapour and carbon dioxide are removed from the sampled gas we can use equations 14 and 15 as follows, where $\mathrm{FACO}_{2}$ is the fraction of carbon dioxide in the alveolar sample. If no measurement of $\mathrm{FACO}_{2}$ is available then a value of 0.05 may be assumed.

$$
\begin{gathered}
V_{\mathrm{ABTPS}}=\left(V_{\mathrm{IATPD}}-V_{\text {Dequip }}-V_{\text {Danat }}\right) \cdot \frac{F_{\mathrm{ITr}}}{F_{\mathrm{ATr}} \cdot\left(1-F_{\mathrm{ACO}_{2}}\right)} \cdot \frac{P_{\mathrm{B}}}{\left(P_{\mathrm{B}}-47\right)} \cdot \frac{310}{(273+T)} \\
V_{\mathrm{ASTPD}}=\left(V_{\text {IATPD }}-V_{\text {Dequip }}-V_{\text {Danat }}\right) \cdot \frac{F_{\mathrm{ITr}}}{F_{\mathrm{ATr}} \cdot\left(1-F_{\mathrm{ACO}_{2}}\right)} \cdot \frac{P_{\mathrm{B}}}{760} \cdot \frac{273}{(273+T)}
\end{gathered}
$$

Where water vapour in the sampled gas is equilibrated to room air, carbon dioxide does not interfere with the analysers and tank values (i.e. the dry gas concentration) are used for FITr, we can use equations 16 
and 17 as shown below. If FITr is read by the analysers, the corrections are the same as in equations 12 and 13 above.

$$
\begin{aligned}
& V_{\text {ABTPS }}=\left(V_{\text {IATPD }}-V_{\text {Dequip }}-V_{\text {Danat }}\right) \cdot \frac{F_{\mathrm{ITr}}}{F_{\mathrm{ATr}}} \cdot \frac{\left(P_{\mathrm{B}}-P_{\mathrm{H}_{2} \mathrm{O}}\right)}{\left(P_{\mathrm{B}}-47\right)} \cdot \frac{310}{(273+T)} \\
& V_{\mathrm{ASTPD}}=\left(V_{\text {IATPD }}-V_{\text {Dequip }}-V_{\text {Danat }}\right) \cdot \frac{F_{\mathrm{ITr}}}{F_{\mathrm{ATr}}} \cdot \frac{\left(P_{\mathrm{B}}-P_{\mathrm{H}_{2} \mathrm{O}}\right)}{760} \cdot \frac{273}{(273+T)}
\end{aligned}
$$

If neither water vapour nor carbon dioxide are removed from the sampled gas, no interference is observed for the analysers and the sample tubing is heated to prevent condensation, we can use equations 18 and 19 as shown below:

$$
\begin{gathered}
V_{\mathrm{ABTPS}}=\left(V_{\mathrm{IATPD}}-V_{\text {Dequip }}-V_{\text {Danat }}\right) \cdot \frac{F_{\mathrm{ITr}}}{F_{\mathrm{ATr}}} \cdot \frac{310}{(273+T)} \\
V_{\mathrm{ASTPD}}=\left(V_{\text {IATPD }}-V_{\text {Dequip }}-V_{\text {Danat }}\right) \cdot \frac{F_{\mathrm{ITr}}}{F_{\mathrm{ATr}}} \cdot \frac{\left(P_{\mathrm{B}}-47\right)}{760} \cdot \frac{273}{(273+T)}
\end{gathered}
$$

In all four cases, temperature is measured in degrees Celsius and gas pressures are measured in mmHg. It is essential that $V \mathrm{D}$ is considered in the calculation of $V \mathrm{~A}$. $V \mathrm{D}$ occurs in two areas: equipment dead-space, $V$ Dequip (i.e. the volume of the mouthpiece, filters and connections within the breathing circuit) and anatomic dead-space, VDanat (i.e. the volume in the conducting airways that does not participate in gas exchange). VDequip must be specified by the equipment manufacturer but may vary as the user alters the system (e.g. by adding a filter or using a different filter). A further small correction to $V \mathrm{D}$ can be made where VDequip is assumed to be under ATPD conditions, since it is filled with room temperature, dry test gas at the end of inspiration, whereas VDanat should be assumed to be under BTPS conditions. There are various methods to estimate VDanat. One example uses a fixed value of $150 \mathrm{~mL}[4,5]$, although this does not work well for small adults or children. Another uses a value of $2.2 \mathrm{~mL} \cdot \mathrm{kg}^{-1}$ of body weight [50], although this does not work well for very obese subjects. In the studies which derive the commonly used reference equations, the latter is the most commonly used technique. However, some investigators have ignored VDanat [91-93] and one uses a value derived from age $+2.2 \mathrm{~mL} \cdot \mathrm{kg}^{-1}$ of body weight [94]. If body mass index (BMI) is $<30 \mathrm{~kg} \cdot \mathrm{m}^{-2}$, the recommendation is to use an estimate for $V$ Danat of $2.2 \mathrm{~mL} \cdot \mathrm{kg}^{-1}$ body weight. In more obese subjects, or if the weight of the subject is unknown, VDanat (in $\mathrm{mL}$ ) can be estimated using equation 20 where height $(\mathrm{h})$ is measured in $\mathrm{cm}$.

$$
V_{\text {Danat }}=\mathrm{h}^{2} / 189.4
$$

With classical discrete-sample systems, which collect the alveolar sample in a collection bag or chamber, the sample-bag residual volume (sometimes called the sample-bag dead-space) dilutes the sample gas and alters the measured concentrations of the expired gases. The size and direction of the error depends on Vs, the residual volume of the sample bag and its connectors (VSRV) and the gas content of this residual volume. VSRV could contain test gas, room air, or expired gas from a subject after a DLCO manoeuvre. When VsRV contains room air, its effect is to reduce the measured concentrations of the expired gases and equation 21 can be used to adjust for this. Estimates of the potential change in DLCO, in existing systems when no adjustment is made for sample-bag dead-space, range from $0.3-8 \%$ depending on the sample-bag size and VSRV [95].

$$
F_{\mathrm{ATr}}[\text { adjusted }]=F_{\mathrm{ATr}}[\text { measured }] \cdot\left(V_{\mathrm{S}} /\left(V_{\mathrm{S}}-V_{\mathrm{SRV}}\right)\right)
$$

For classical systems, manufacturers must report instrument and sample-bag dead-space. Both of these must be flushed with room air or, if $D M$ and $V C$ are to be calculated, appropriate levels of oxygen before the single-breath manoeuvre such that they will not contain expiratory gas from a previous subject. VSRV must be $<2 \%$ of Vs or $10 \mathrm{~mL}$, whichever is larger. Importantly, when RGAs are used to measure the exhaled sample, there is no residual bag volume to consider ( $V \mathrm{~A}$ is calculated using a mass balance of all inhaled and exhaled gas; equations $22-26$ in the next section).

For normal subjects, the classical single-breath determination of alveolar volume (VAsb) described above closely matches TLC determined by plethysmography $[22,74]$. However, poor gas mixing in patients with 
maldistribution of inspired volume (e.g. patients with obstructed airways) can markedly alter tracer gas dilution leading to values for VAsb that are markedly less than the value of VA determined from the actual total thoracic gas volume. Observed carbon monoxide uptake is also affected by poor gas mixing under these conditions and will primarily reflect the carbon monoxide transfer properties of the regions into which the test gas is distributed. It has been suggested that a separately determined VA value from a more accurate method (e.g. multiple-breath technique (VAmb) or plethysmography (VAplethys)) could be substituted for VAsb under these conditions to correct for the effects of maldistribution. However, the DLCO calculation (equation 7) is based on the volume of gas into which the tracer gas (and carbon monoxide) distributes, and not the total thoracic gas volume. Moreover, substituting a larger, separately determined VAmb or VAplethys value assumes that $D \mathrm{M}$ and $V \mathrm{C}$ properties in the unmeasured lung regions are similar to those in the measured lung regions, an assumption that is difficult to justify. Additionally, if VAsb is replaced with a different value, the applicability of the DLCO reference equations is compromised.

Due to these considerations, a separately measured VAmb or VAplethys should not be substituted for VAsb. Instead, when the value of VAsb is markedly less than that determined separately for VAmb or VAplethys, this must be reported and the ratio of VAsb to VAmb or VAplethys may optionally be included. For the subsequent interpretation of DLCO, it should then be noted that the maldistribution of inspired gas probably contributes to any observed reduction in measured values.

\section{Alveolar volume in RGA systems}

As mentioned in the previous section, when an RGA system is used the dead-space volume is measured rather than estimated. The total dead-space, $V \mathrm{D}$, can be measured from the tracer gas washout curve using the FowLER [78] method (figure 6). A linear regression line estimating the slope of phase III of the tracer gas washout concentration as a function of volume should be calculated using the last half of the expiratory tracing by volume. The Fowler dead-space is the point where the area between the phase III slope and the
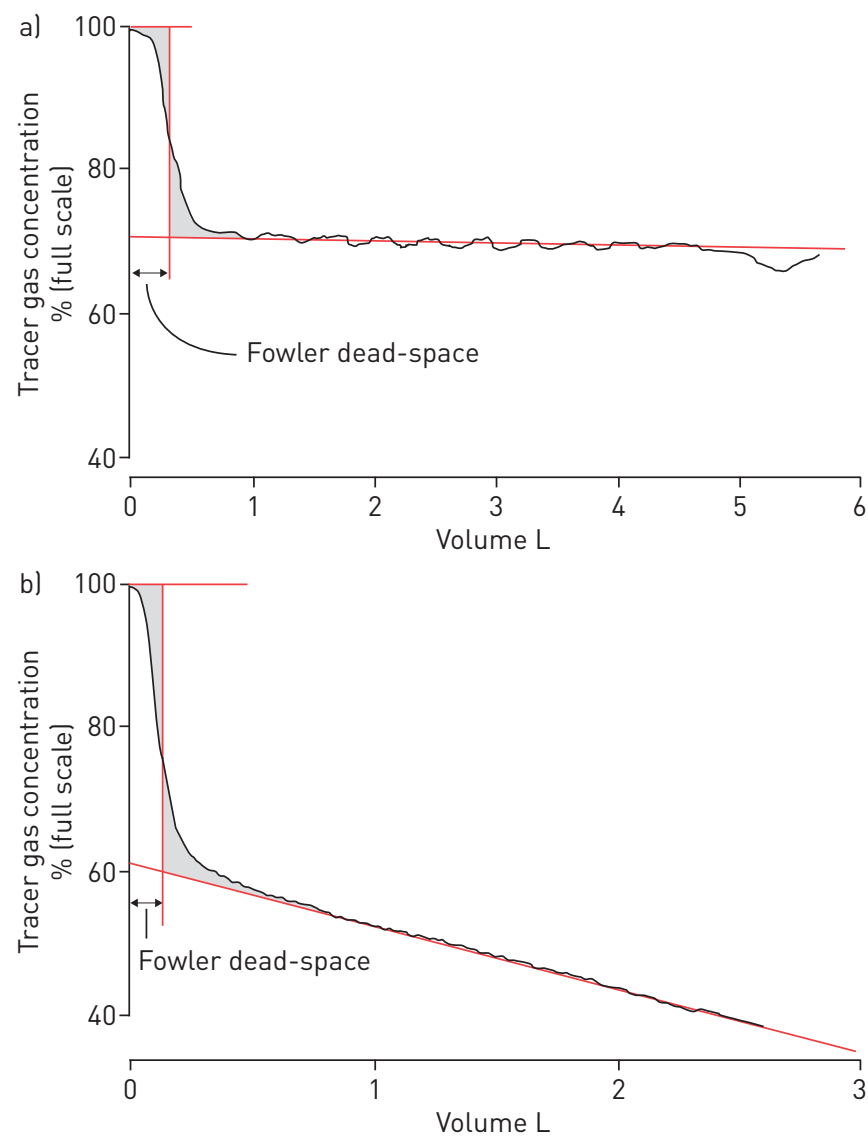

FIGURE 6 Graphical representation of the calculation of the Fowler dead-space volume in a normal, healthy subject (a) and a subject with chronic obstructive pulmonary disease (COPD) (b). The single-breath tracer gas washout is plotted against exhaled lung volume from total lung capacity. The volume at which the shaded area above the tracer gas washout curve equals the shaded area below the curve is the FowLER dead-space [78] which is reported under body temperature, ambient pressure, saturated with water vapour (BTPS) conditions. 
tracer gas washout curve equals the area between the peak tracer gas concentration and the tracer gas washout curve. The anatomic dead-space, VDanat, is equal to the Fowler dead-space minus the equipment dead-space, VDequip, which includes the filter and/or mouthpiece and which must be supplied by the manufacturer.

The development of RGA systems now allows the analysis of all gas exhaled and provides the opportunity to enhance the accuracy of VA determinations. Given that the tracer gas can now be monitored throughout exhalation, there is no need to constrain the measurement of $V A$ to the discrete sample computationally constructed to determine carbon monoxide uptake. Indeed, using all of the available gas concentration data has been shown to provide a better estimate of $V A[71,96]$ than constraining the measurement to a smaller sample of exhaled gas (as was required by the equipment available in 1957 when the clinical single-breath method was developed [2]).

This technique uses a mass balance approach to determine $V \mathrm{~A}$ in which the volume of tracer gas inhaled and the volume subsequently exhaled are measured and the latter subtracted from the former to determine the volume of tracer gas remaining in the lung at end-exhalation $[71,96]$. The volume of tracer gas left in the lung is then divided by the end-expiratory tracer gas concentration to give the absolute end-expiratory lung volume $V$ ee. The TLC is then calculated by adding the expired volume ( $V \mathrm{E})$ to Vee and subtracting $V$ Dequip. If $V E$ is the volume expired from the maximum volume during breath-holding (to the end of the manoeuvre) then the single-breath total lung capacity (TLCsb) can be defined as TLCsb $=V E+V e-V$ Dequip and $V A=T L C s b-V$ Danat. Residual tracer gas in the lung from a previous manoeuvre can be measured prior to the start of the current manoeuvre and included in the mass balance equation.

In more detail, $V A$ is calculated using a mass balance equation which states that the tracer gas left in the lung at end exhalation is equal to all of the tracer gas inhaled minus the tracer gas exhaled. The sum of the inhaled and exhaled tracer gas volumes is the integral, with respect to time, of flow $\times$ tracer gas concentration where flow is positive for inhalation and negative for exhalation. In this case, Vee (including $V$ Dequip and VDanat) is thus described by equation 22 where $t 0$ is the time at the start of test gas inhalation, $t \mathrm{f}$ is the time at the end of exhalation, $\operatorname{Tr}(t)$ is the tracer gas concentration at any time $t$ (adjusted to BTPS conditions), $\operatorname{Tr}_{\mathrm{ee}}$ is the mean tracer gas concentration at end-exhalation and flow $(t)$ is the flow at any time $t$ (under BTPS conditions).

$$
V_{\mathrm{ee}}=\frac{1}{\operatorname{Tr}_{\mathrm{ee}}} \int_{t_{0}}^{t_{\mathrm{f}}} \operatorname{Tr}(t) \cdot \text { flow }(t) d t
$$

Depending upon the signal to noise ratio, the average value of $\operatorname{Tr}$ over the last $250 \mathrm{~mL}$ can be used for $\operatorname{Tr}_{\text {ee }}$. Furthermore, when flow $(t)$ is positive during inhalation of dry test gas, it is adjusted by $310 / T \cdot P \mathrm{~B} /$ $(P \mathrm{~B}-47)$ where $T$ is the ambient temperature. All measurements of tracer gas are assumed to be made with the water vapour pressure in the sample line equilibrated to the water vapour pressure in room air.

The absolute lung volume at any time $t, V(t)$, during the manoeuvre can then be described by equations 23 and 24. The integral of flow $(t) d t$ from time $t_{0}$ to time $t_{\mathrm{f}}$ is the net change in total volume over the entire manoeuvre and will be zero if the inhaled volume, VI, equals the exhaled volume, VE. The integral of flow $(t) d t$ from time $t_{0}$ to time $t$ is the net volume change at any time $t$. Hence, at the end of the single breath manoeuvre, $V\left(t_{\mathrm{f}}\right)$ is simply equal to $V e e-V$ Dequip.

$$
\begin{gathered}
V(t)=V_{\mathrm{ee}}+\int_{t_{0}}^{t} \text { flow }(t) d t-\int_{t_{0}}^{t_{\mathrm{f}}} \text { flow }(t) d t-V_{\text {Dequip }} \\
V(t)=V_{\mathrm{ee}}-\int_{t}^{t_{\mathrm{f}}} \text { flow }(t) d t-V_{\text {Dequip }}
\end{gathered}
$$

If the tracer gas has not been completely washed out from a previous DLCO manoeuvre, then the residual alveolar tracer gas concentration (TrR) measured just prior to the inhalation of test gas must be considered in the mass-balance equation and $V e e$ is duly described by equation 25 .

$$
V_{\text {ee }}=\frac{1}{\left(\operatorname{Tr}_{\mathrm{ee}}-\operatorname{Tr}_{\mathrm{R}}\right)} \int_{t_{0}}^{t_{\mathrm{f}}}\left(\operatorname{Tr}(t)-\operatorname{Tr}_{\mathrm{R}}\right) \cdot \text { flow }(t) d t
$$


The value of VA to be reported in BTPS conditions is described by equation 26. This value is converted to STPD conditions for use in equation 8 or 9.

$$
V_{\mathrm{A}}=V_{\mathrm{E}}+V_{\mathrm{ee}}-V_{\text {Danat }}-V_{\text {Dequip }}
$$

This method has been compared to plethysmography in normal subjects and in patients with lung disease with various breath-hold times $[71,96]$. For normal subjects, there is little difference in DLCO when using either method to measure VA; however, VA measured by the RGA method is significantly higher than VA measured by the classical method in subjects with COPD or uncontrolled asthma. The resulting DLCO measurements in COPD cases are some 8 to 15\% higher. Since reference values for DLCO are developed using normal subjects, existing reference values continue to be applicable using VA measured by the RGA method. For subjects with COPD the effect of using the RGA VA value will, in isolation, be to calculate an increased DLCO value. However, the VA measured from a discrete sample will vary with the sample volume and sample timing [72] such that using the RGA VA value should improve reproducibility of DLCO in these subjects.

Another significant advantage of calculating absolute lung volume at end-exhalation instead of at maximal inhalation is that the impact of errors due to the assumption of complete gas mixing in the lung is reduced. For example, in a patient with a TLC of $7 \mathrm{~L}$ and a RV of $2 \mathrm{~L}$, a $10 \%$ error in TLC (700 $\mathrm{mL}$ ) translates into a $10 \%$ error in DLCO. However, a $10 \%$ error in RV would be $200 \mathrm{~mL}$ and when VC is added to RV the volume error at TLC is only $2.9 \%$ which translates into only a $2.9 \%$ error in DLCO.

During the transition from classical systems to RGA systems, some laboratories may wish to report DLCO values using the 2005 ATS/ERS method in combination with those obtained using RGA VA for comparative purposes. RGA VA values may alter DLCO in some older normal subjects, who have more heterogeneous distribution of ventilation due to the normal ageing process, and therefore might yield slightly higher DLCO values compared to current classically derived reference values. As with any set of reference values, which must be validated in each laboratory, DLCO values using VA must be validated using a group of normal, healthy subjects. The Global Lung Function Initiative is in the process of developing all-age predicted values using datasets submitted from 12 countries (www.lungfunction.org).

\section{Inspired gas conditions}

In most cases, the test gas inspired from a bag or a compressed gas cylinder with a demand valve is a dry gas and, as such, is considered to be under ATPD conditions. The inspired volume needs to be converted into BTPS conditions for use in equations 10 and 11. It is recommended that the VI (BTPS) be reported and that manufacturers should specify and document inspired gas conditions for each instrument. Since gas cooling can occur due to decompression through the delivery valve, manufacturers are required to measure the test gas temperature at the pneumotachometer in a typical system in their testing laboratory and provide appropriate compensation for gas cooling if necessary.

\section{Carbon dioxide, water vapour and temperature adjustment for alveolar volume calculations}

Exhaled gas contains carbon dioxide and water vapour which were not present in the test gas mixture. As noted previously, some systems remove one or both of these if they interfere with analyser function, raising both carbon monoxide and tracer gas concentrations. Under these circumstances, adjustments are required for the increase in FATr used to calculate VA. However, no adjustment for the increase in alveolar inspired carbon monoxide and tracer gas fractions at time $\mathrm{t}\left(F_{\mathrm{ACO}, \mathrm{t}}\right.$ and $\left.F_{\mathrm{ATr}} \mathrm{t}\right)$ is necessary in calculating the rate of carbon monoxide uptake, since the concentration factor appears in both the numerator and the

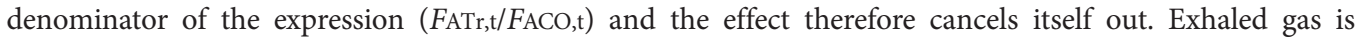
initially at body temperature and some systems allow this to cool, such that the gas volume contracts, whereas others will provide heat to maintain the temperature. As such, adjustments to BTPS conditions may be required depending upon the system design. All of these adjustments must be documented by the manufacturer for their particular system. The conversion factors used to modify calculations in DLCO manoeuvres are shown in equations 8,9 and 12-19.

\section{RGA signal alignment}

To properly analyse continuous gas samples, the gas concentration signals from the analysers must be properly aligned with the flow signal from the pneumotachometer (figure 2). The first step is to shift the concentration signal ahead in time to compensate for the lag time (the time required for the gas to travel from the aspiration port to the analyser chamber). The lag time is a function of the length and diameter of the tubing and the analyser aspiration rate. The length of the tubing should be minimised to prevent mixing of the aspirated sample within the sampling tube, which can blunt the response time through a process of Taylor dispersion. The amount of mixing will also depend on the configuration of the sampling 
circuit, including any valves and junctions, which can create turbulence. It should also be noted that lag time can vary with gas viscosity and, when helium is used as the tracer gas, this may require dynamic compensation during exhalation.

An additional shift of each gas concentration signal relative to the flow signal is also required to compensate for the response time of the analyser. This can be accomplished using an optimal shift equal to the natural logarithm of twice the time constant of the analyser response [97]. Alternatively, alignment may be achieved by other signal processing strategies such as cross-correlation techniques (convolution of signals).

For a more accurate DLCO calculation, a third shift equal to the dead-space transit time may be used to translate the gas concentrations measured at the mouth to the gas concentrations in the alveolar space. During inhalation, the gas sampled at the aspiration port will not reach the gas-exchanging alveolar space until at least one dead-space transit time later and, similarly, the gas sampled at the aspiration port during exhalation is gas that was in the alveolar space one dead-space transit time previously. If a system uses this further correction the effective breath-hold time in the alveolar space will be reduced (typically by $0.05-$ $0.15 \mathrm{~s}$ ) and DLCO will be increased (typically by $0.5-1.5 \%$ ).

Interpolation between data points may be required to achieve optimal shifting of the gas concentration data, particularly if lower digitisation rates are used. To reduce errors introduced by interpolation, a sample rate of $1000 \mathrm{~Hz}$ per channel is recommended.

\section{Transfer coefficient of the lung for carbon monoxide}

The logarithmic change in carbon monoxide concentration during the breath-hold phase of the single-breath manoeuver, divided by $t \mathrm{BH}$ and the $P \mathrm{~B}$ of the dry gas is termed $K \mathrm{CO}$. This is equivalent to the left hand side of equation 5 without the VA term and, conceptually, DLCO is thus equivalent to VA.KCO. The specific calculations for KCO are shown below as equations 27 and 28; however, if values are required in SI units, it is necessary to convert $1000 \mathrm{~mL}(\mathrm{STPD})$ to $\mathrm{mmol}$ as shown in equations 29 and 30.

$$
\begin{gathered}
K_{\mathrm{CO}}=\ln \left(\frac{F_{\mathrm{ICO}}}{F_{\mathrm{ACO}}} \cdot \frac{F_{\mathrm{ATr}}}{F_{\mathrm{ITr}}}\right) \cdot \frac{1}{t_{\mathrm{BH}} / 60 \cdot\left(P_{\mathrm{B}}-P_{\mathrm{H}_{2} \mathrm{O}}\right)} \cdot \frac{1000 \mathrm{~mL}}{1 \mathrm{~L}} \cdot \frac{273}{310} \cdot \frac{P_{\mathrm{B}}-P_{\mathrm{H}_{2} \mathrm{O}}}{760} \\
K_{\mathrm{CO}}=\ln \left(\frac{F_{\mathrm{ICO}}}{F_{\mathrm{ACO}}} \cdot \frac{F_{\mathrm{ATr}}}{F_{\mathrm{ITr}}}\right) \cdot \frac{1}{t_{\mathrm{BH}}} \cdot 69.52 \\
K_{\mathrm{CO}}=\ln \left(\frac{F_{\mathrm{ICO}}}{F_{\mathrm{ACO}}} \cdot \frac{F_{\mathrm{ATr}}}{F_{\mathrm{ITr}}}\right) \cdot \frac{1}{t_{\mathrm{BH}} / 60 \cdot\left(P_{\mathrm{B}}-P_{\mathrm{H}_{2} \mathrm{O}}\right)} \cdot \frac{1000 \mathrm{~mL}}{1 \mathrm{~L}} \cdot \frac{273}{310} \cdot \frac{P_{\mathrm{B}}-P_{\mathrm{H}_{2} \mathrm{O}}}{101.3} \cdot \frac{1 \mathrm{mmol}}{22.4 \mathrm{~mL}} \\
K_{\mathrm{CO}}=\ln \left(\frac{F_{\mathrm{ICO}}}{F_{\mathrm{ACO}}} \cdot \frac{F_{\mathrm{ATr}}}{F_{\mathrm{ITr}}}\right) \cdot \frac{1}{t_{\mathrm{BH}}} \cdot 23.29
\end{gathered}
$$

It should be noted that the calculation of KCO is completely independent of the gas flow, lung volume and barometric pressure measured during the manoeuvre. Although the units of the logarithmic change in carbon monoxide concentration per unit time and per unit pressure are $\min ^{-1} \cdot \mathrm{mmHg}^{-1}$ (or $\mathrm{min}^{-1} \cdot \mathrm{kPa}^{-1}$ ), KCO is expressed in units of $\mathrm{mL}(\mathrm{STPD}) \cdot \mathrm{min}^{-1} \cdot \mathrm{mmHg}^{-1} \cdot \mathrm{L}(\mathrm{BTPS})^{-1}$ or $\mathrm{mmol} \cdot \mathrm{min}^{-1} \cdot \mathrm{kPa}^{-1} \cdot \mathrm{L}(\mathrm{BTPS})^{-1}$ only because the basic measurement of the logarithmic change in gas concentration over time is multiplied by $1000 \mathrm{~mL}(\mathrm{STPD})$ and then divided by $1 \mathrm{~L}$ (BTPS) which changes the magnitude of the value of KCO by 1000 times the BTPS to STPD factor [98].

As $V \mathrm{~A}$ is not a component of $\mathrm{KCO}$, some users prefer to use $\mathrm{KCO}$ as it eliminates the uncertainty in measurement of $V \mathrm{~A}$ from the assessment of carbon monoxide uptake. This uncertainty arises from the assumption that FATr, as measured from the exhaled gas sample, is representative of the entire lung. However, this same assumption is used to estimate the alveolar carbon monoxide concentration at the start of breath-holding and KCO measurement is thus subject to the same uncertainty [99].

Mathematically, KCO can be calculated as DLCO/VABTPS. However, KCO should not be reported using the term $D \mathrm{LCO} / V \mathrm{~A}$, as it may be inferred from this term that DLCO can be corrected or normalised for VA. In fact, the relationship between lung volume and carbon monoxide uptake is complex and studies evaluating the effects of reduced $V$ I (and thus $V A$ ) show the relationship to be alinear and certainly less than 1:1 
(i.e. the fall in DLCO is far less than the fall in lung volume) $[20,21,98,100,101]$. This likely reflects the fact that alveolar folding-unfolding and capillary volume changes resulting from lung volume changes do not translate into concomitant and equal changes in DLCO. Thus, while the KCO calculation might add insight into carbon monoxide uptake properties of the lung [98], it cannot be used as a simple technique to normalise DLCO for volume.

\section{Optional calculations}

Separate equations for inhalation, breath-hold and exhalation

When KROGH [1] developed the measurement of the "diffusion constant" in 1915, she had to design a manoeuvre that would be compatible with an analytical solution of the equation for gas transfer. She achieved this by simulating a pure breath-hold manoeuvre and the measurement of DLCO today continues to be constrained by having the patient perform a rapid inhalation, $10 \mathrm{~s}$ of breath-holding and a rapid exhalation. Deviations from a pure breath-hold manoeuvre cause errors in DLCO because the Krogh equation is only valid for this case $[68,72]$.

The gas transfer equation can also be written for inhalation and exhalation, both of which become equivalent to the breath-holding equation at zero flow. Using data from the continuous monitoring of flow and the concentrations of carbon monoxide and tracer gas throughout the manoeuvre, an algorithm can be used to calculate DLCO by numerical methods [53]. This method accounts analytically for the times of inhalation and exhalation, gives values of DLCO that are not dependent on how rapidly the manoeuvre is performed and returns a fixed value of DLCO over the entire manoeuvre that accounts for the observed uptake of carbon monoxide. All of the exhaled gas data can be used to provide a more representative measurement of DLCO for the whole lung rather than calculating DLCO from a small alveolar gas sample.

Using the "three-equation method" [53] in young, healthy subjects, the standardised manoeuvre gives the same values for DLCO as the ATS standardised manoeuvre. However, when these same subjects perform the manoeuvre with slower flows and/or shorter breath-hold times, similar to those seen in patients with airflow obstruction, the three-equation method gives unchanged DLCO values while the ATS standardised method yields significantly higher DLCO values [68]. KROGH [1] designed her experiment for normal subjects and not for patients with lung disease. The standardised manoeuvre penalises lung disease patients, who cannot perform it adequately; however, with RGA instrumentation it is no longer necessary to use an arduous, demanding manoeuvre to measure DLCO.

\section{Indices of heterogeneity of ventilation and gas transfer}

As noted above, the heterogeneity of ventilation affects DLCO measurement [102, 103]. Gas concentration data from RGA systems can be used to calculate indices of ventilation nonuniformity, such as the slope of phase III of the alveolar plateau [90, 104]. However, such indices need to be normalised to account for the differences in lung volume and the differences in RV/TLC that occur from person to person [79]. Other measures of mixing efficiency may be calculated from the tracer gas data [53].

Disease processes can also affect the distribution of gas transfer in the lung. Using the three-equation method, the observed decay in carbon monoxide during exhalation can be compared to the carbon monoxide decay that would be predicted for a homogeneous lung in which diffusion occurs uniformly. An index of DLCO heterogeneity has been developed that is capable of distinguishing smokers with normal lung function and normal DLCO from a control group of nonsmokers [105].

\section{Evaluating the measurement of DLco \\ Acceptability, repeatability and quality control}

Acceptable manoeuvres are defined in table 3. The volume-time graph should show a smooth, sharp rise in volume, followed by a stable breath-hold and a smooth, sharp exhalation (figure 3). The gas concentration graph should show a very sharp rise when test gas is introduced and remain stable until exhalation followed by an initial rapid decline with a smooth transition to phase III. Variations from this pattern will indicate leaks. The VI of test gas must be at least $90 \%$ of the largest VC measured in the same pulmonary function testing session. At least $85 \%$ of test gas $V$ I must be inhaled within $<4 \mathrm{~s}$. There must be no evidence of a Müller or Valsalva manoeuvre during the breath-hold period. Alveolar sample collection must be completed within $4 \mathrm{~s}$. The calculated breath-hold time must be $10 \pm 2 \mathrm{~s}$. For RGA systems, virtual sample collection should be initiated after the completion of dead-space washout. A manoeuvre with a $\mathrm{VI} / \mathrm{VC}<90 \%$ but $\geqslant 85 \%$ may be deemed acceptable if the $\mathrm{VA}$ is within $200 \mathrm{~mL}$ or $5 \%$ (whichever is greater) of the largest $V$ A from other acceptable manoeuvres.

Repeatability describes intra-session variability on repeated testing when there is no change in test conditions [106, 107]. In a large university-based laboratory study, the coefficient of variation for repeated measurement in normal subjects was $3.1 \%$ and this increased only slightly (from 4.0 to $4.4 \%$ ) in patients 
TABLE 3 Acceptability, repeatability and quality control in DLco testing

\section{Criteria for acceptability}

$A V_{1} \geqslant 90 \%$ of the largest $V C$ in the same test session; alternatively a $V_{1} \geqslant 85 \%$ of the largest $V C$ in the same test session and $V_{A}$ within $200 \mathrm{~mL}$ or $5 \%$ (whichever is greater) of the largest $V_{A}$ from other acceptable manoeuvres

$85 \%$ of test gas $V_{1}$ inhaled in $<4 \mathrm{~s}$

A stable calculated breath-hold for $10 \pm 2 \mathrm{~s}$ with no evidence of leaks or Valsalva/Müller manoeuvres during this time

Sample collection completed within $4 \mathrm{~S}$ of the start of exhalation. For RGA systems, virtual sample collection should be initiated after dead-space washout is complete

\section{Criteria for repeatability}

At least two acceptable DLco measurements within $2 \mathrm{~mL} \cdot \mathrm{min}^{-1} \cdot \mathrm{mmHg}^{-1}\left(0.67 \mathrm{mmol} \cdot \mathrm{min}^{-1} \cdot \mathrm{kPa}^{-1}\right)$ of each other

\begin{tabular}{lccc}
\hline & & Quality control grading & \\
\hline Score & $\boldsymbol{V} \mathbf{I} / \mathbf{V C}$ & $\boldsymbol{t}$ BH & Sample collection \\
\hline $\mathrm{A}$ & $\geqslant 90 \% 9$ & $8-12 \mathrm{~s}$ & $\leqslant 4 \mathrm{~s}$ \\
$\mathrm{~B}$ & $\geqslant 85 \%$ & $8-12 \mathrm{~s}$ & $\leqslant 4 \mathrm{~s}$ \\
$\mathrm{C}$ & $8-12 \mathrm{~s}$ & $\leqslant 5 \mathrm{~s}$ \\
$\mathrm{D}$ & $\leqslant 80 \%$ & $<8$ or $>12 \mathrm{~s}$ & $\leqslant 5 \mathrm{~s}$ \\
$\mathrm{~F}$ & $\leqslant 80 \%$ & $<8$ or $>12 \mathrm{~s}$ & $>5 \mathrm{~s}$
\end{tabular}

$V_{I}$ : inspired volume; $V C$ : vital capacity; $V_{A}$ : alveolar volume; $t B H$ : breath-hold time; $D\llcorner C 0$ : diffusing capacity of the lung for carbon monoxide. ${ }^{\#}$ : only grade A manoeuvres meet all acceptability criteria. The average DLco values from two or more grade A manoeuvres that meet the repeatability criterion should be reported. If only one grade A manoeuvre is attained, the DLCo value from that manoeuvre should be reported. If no grade A manoeuvre is obtained, manoeuvres of grades B to D might still have clinical utility. The average of such manoeuvres should be reported but these deviations from the acceptability criteria must be noted to caution the interpreter of the test results. Manoeuvres of grade $\mathrm{F}$ are not useable. " : or $V_{1} / \mathrm{VC} \geqslant 85 \%$ and $V_{\mathrm{A}}$ within $200 \mathrm{~mL}$ or $5 \%$ (whichever is greater) of the largest $V_{A}$ from another acceptable manoeuvre.

with abnormal spirometry patterns [108]. Studies conducted prior to the publication of the 2005 standards found DLCO variability of up to 9\% (reproducibility) in normal individuals in repeated measurement over a period of 1 year [109] and coefficients of variation ranged from $6.2 \%$ to $12 \%$ in selected UK regions [110].

Repeatability requirement: there must be at least two acceptable manoeuvres that are within $2 \mathrm{~mL} \cdot \mathrm{min}^{-1} \cdot \mathrm{mmHg}^{-1}\left(0.67 \mathrm{mmol} \cdot \mathrm{min}^{-1} \cdot \mathrm{kPa}^{-1}\right)$ of each other. A study of 4797 test sessions found that $95.5 \%$ of cases met this criterion [67]. Since most intra-session variability is technical rather than physiological, the mean of acceptable manoeuvres is reported. The average of at least two acceptable manoeuvres that meet the repeatability requirement must be reported (i.e. outliers excluded). While it is recommended that at least two acceptable DLCO manoeuvres must be performed, research is needed to determine the actual number of manoeuvres required to provide a reasonable estimate of average DLCO for a given person. As noted elsewhere, five manoeuvres will result in an increase of $\sim 3.5 \% \mathrm{COHb}$ from baseline $[66,82]$, which will decrease the measured DLCO by $\sim 3-3.5 \%$. Thus, conducting more than five manoeuvres is not a recommended strategy.

There are no quality control grading systems that have been validated using the new standards contained in this document. Until such validation is published, an interim grading system is provided in table 3 and further research is recommended to develop and validate a DLCO grading system.

A grade A manoeuvre meets all acceptability criteria. The average DLCO from two or more grade A manoeuvres that are repeatable (i.e. are within $2 \mathrm{~mL} \cdot \mathrm{min}^{-1} \cdot \mathrm{mmHg}^{-1}$ or $0.67 \mathrm{mmol} \cdot \mathrm{min}^{-1} \cdot \mathrm{kPa}^{-1}$ of each other) should be reported. If, after repeat testing, the operator is unable to obtain two repeatable grade A manoeuvres, then the following values are reported with a caution to the interpreter that the testing session was suboptimal: 1) If two or more grade A manoeuvres that are not repeatable are obtained, then the average DLCO value from the acceptable manoeuvres is reported. 2) If only one grade A manoeuvre is obtained, then the DLCO value from that manoeuvre is reported. 3) If no acceptable manoeuvres are obtained, then the average DLCO value of the manoeuvres with grades B, C or D is reported. 4) If only grade F manoeuvres are obtained, then no DLCO value is reported. 
Adjustments to the predicted value of DLco prior to interpretation

The value of DLCO depends upon a number of physiological factors. Besides varying with age, sex, height and possibly ethnicity, DLCO also changes with $\mathrm{Hb}$, lung volume, $\mathrm{COHb}, \mathrm{PIO}_{2}$ (inspired oxygen tension, e.g. altitude), exercise and body position. Although these effects may cause changes in DLCO in opposite directions [111], all should be considered in interpreting the observed carbon monoxide uptake. It is recommended that adjustments for these factors be made in the predicted rather than the measured DLCO value. The predicted DLCO value is derived from measurements in normal subjects who are disease free, have normal $\mathrm{Hb}$ levels and minimal $\mathrm{COHb}$, are sitting at rest, and breathing room air. If any of these conditions are not met, then the predicted value should be adjusted accordingly.

\section{Adjustment for haemoglobin}

Since carbon monoxide- $\mathrm{Hb}$ binding is such an important factor in carbon monoxide transfer, DLCO changes can be substantial as a function of $\mathrm{Hb}$ concentration [111-115]. The empirical effect upon DLCO with change in $\mathrm{Hb}$ closely matches what is expected from a theoretical approach using the relationship in equation 3, with $\theta$ assumed to be proportional to $\mathrm{Hb}, D \mathrm{M} / \theta V \mathrm{C}$ assumed to be 0.7 [113] and the "standard" $\mathrm{Hb}$ value assumed to be $14.6 \mathrm{~g} \cdot \mathrm{dL}^{-1}\left(9 \mathrm{mmol} \cdot \mathrm{L}^{-1}\right)$ in adult and adolescent males and $13.4 \mathrm{~g} \cdot \mathrm{dL}^{-1}$ $\left(8.26 \mathrm{mmol} \cdot \mathrm{L}^{-1}\right)$ in adult females and children $<15$ years old. Using these relationships and expressing $\mathrm{Hb}$ in $\mathrm{g} \cdot \mathrm{dL}^{-1}$, the predicted DLCO in adolescents and adult males can be adjusted using equation 31 , while that in children $<15$ years of age and females is adjusted using equation 32 . Results from a more recent study in patients with a wide range of $\mathrm{Hb}$ abnormalities [115] show a slightly greater and more linear relationship; however, corrected values are generally consistent with equations 31 and 32.

$$
\begin{gathered}
D_{\mathrm{LCO}}[\text { predicted for } \mathrm{Hb}]=D_{\mathrm{LCO}}[\text { predicted }] \cdot(1.7 \mathrm{Hb} /(10.22+\mathrm{Hb})) \\
D_{\mathrm{LCO}}[\text { predicted for } \mathrm{Hb}]=D_{\mathrm{LCO}}[\text { predicted }] \cdot(1.7 \mathrm{Hb} /(9.38+\mathrm{Hb}))
\end{gathered}
$$

The measurement of $\mathrm{Hb}$ in the American population [116] found deviation from these standard values, especial in males, children and seniors; differences were also found between Caucasian and African-Americans. Furthermore, the survey found that $\mathrm{Hb}$ levels in the general population are changing over time. If a more appropriate reference $\mathrm{Hb}$ level (Hbref) is available then the predicted DLCO is adjusted using equation 33 .

$$
D_{\mathrm{LCO}}[\text { predicted for } \mathrm{Hb}]=D_{\mathrm{LCO}}[\text { predicted }] \cdot\left(1.7 \mathrm{Hb} /\left(0.7 \mathrm{Hb}_{\mathrm{ref}}+\mathrm{Hb}\right)\right)
$$

\section{Adjustments for alveolar oxygen tension}

As noted previously, $\mathrm{PAO}_{2}$ affects the measurement of DLCO and changes to $\mathrm{PAO}_{2}$ (such as supplemental oxygen breathing that gives higher $\mathrm{PAO}_{2}$ values) will have a correlating effect on DLCO values. The value of DLCO will change by $\sim 0.35 \%$ for each $1 \mathrm{mmHg}$ change in $\mathrm{PAO}_{2}$ or $\sim 2.6 \%$ for each $1 \mathrm{kPa}$ change in $P_{\mathrm{AO}_{2}}[117$, 118]. Adjustments to the predicted DLCO in a subject on supplemental oxygen may be made using a measured $P_{\mathrm{AO}}$ and assuming a normal $\mathrm{PAO}_{2}$ breathing room air at sea level of $100 \mathrm{mmHg}(13.3 \mathrm{kPa})$. This is shown in equation 34 below or equation 35 if SI units are preferred.

$$
\begin{aligned}
& D_{\mathrm{LCO}}\left[\text { predicted for elevated } P_{\mathrm{AO}_{2}}\right] \approx D_{\mathrm{LCO}}[\text { predicted }] /\left(1.0+0.0035\left(P_{\mathrm{AO}_{2}}-100\right)\right) \\
& T_{\mathrm{LCO}}\left[\text { predicted adjusted for } P_{\mathrm{AO}_{2}}\right] \approx T_{\mathrm{LCO}}[\text { predicted }] /\left(1.0+0.026\left(P_{\mathrm{AO}_{2}}-13.3\right)\right)
\end{aligned}
$$

Some pulmonary function systems include measurement of carbon dioxide. In these systems, the end-expiratory carbon dioxide concentration can be used to estimate the alveolar oxygen partial pressure using the simplified alveolar gas equation. In patients who have higher carbon dioxide levels (higher $\mathrm{PACO}_{2}$ ) and consequently lower $\mathrm{PAO}_{2}$ values, the predicted $\mathrm{DLCO}$ can be corrected to compensate for the increase in DLCO that arises. For example, at a barometric pressure of $760 \mathrm{mmHg}(101.3 \mathrm{kPa})$, if the $P_{\mathrm{ACO}_{2}}$ in a patient retaining carbon dioxide was $50 \mathrm{mmHg}(6.67 \mathrm{kPa})$ then the $\mathrm{PAO}_{2}$ would be $86 \mathrm{mmHg}(11.5 \mathrm{kPa})$ and the predicted DLCO would be $4.8 \%$ higher than if the $P_{\mathrm{ACO}_{2}}$ were $40 \mathrm{mmHg}(5.33 \mathrm{kPa})$. However, there are many assumptions inherent in this approach and more research is needed to determine the validity of such an adjustment. 
Adjustment for carboxyhaemoglobin concentration and carbon monoxide back-pressure

As noted previously, $\mathrm{COHb}$ can affect the measured uptake of carbon monoxide in the following two ways [119-121]. First, by occupying Hb binding sites, carbon monoxide produces an "anaemia effect". Secondly, carbon monoxide partial pressure in the blood will reduce the driving pressure for carbon monoxide transport from alveolar gas to capillary blood. Exposure to ordinary environmental carbon monoxide and endogenous production of carbon monoxide as a byproduct of $\mathrm{Hb}$ catabolism commonly results in measured $\mathrm{COHb}$ levels of 1-2\% [119]. However, cigarette smoke and other environmental sources can produce measurable levels of carbon monoxide back-pressure and $\mathrm{COHb}$ that may need to be considered in the measurement of carbon monoxide uptake [119].

The inhalation of carbon monoxide in the single-breath manoeuvre causes $\mathrm{COHb}$ to increase by $0.6-0.7 \%$ for each manoeuvre $[66,82]$. The adjustment of the predicted DLCO value for carbon monoxide was found to be $-0.938 \%$ per $1.0 \%$ increase in $\mathrm{COHb}$ [122]. For RGA systems, carbon monoxide back-pressure can be measured in expired gas prior to the inspiration of test gas in the DLCO manoeuvre [62] and can be compensated for analytically. For classical systems, carbon monoxide back-pressure can be estimated using one of several available techniques [121, 123-125]. For example, carbon monoxide back-pressure can be calculated from $\mathrm{COHb}$ using equation 36 , where $\mathrm{COHb}$ and $\mathrm{O}_{2} \mathrm{Hb}$ are the fractions of carbon monoxide and oxygen-bound haemoglobin, respectively.

$$
F_{\mathrm{ACO}}=\left(\mathrm{COHb} / \mathrm{O}_{2} \mathrm{Hb}\right) \cdot\left(F_{\mathrm{AO}_{2}}\right) / 210
$$

DLCO can then be recalculated after subtracting the estimated carbon monoxide back-pressure from both the initial and final alveolar carbon monoxide partial pressures (units must be consistent before making the subtraction). Unfortunately, this method will not adjust DLCO for the "anaemia effect" of COHb; however, several studies have evaluated both the empirical and theoretical effects of COHb on DLCO and incorporated both the back-pressure and the "anaemia effect" of COHb into the adjustment. In general, a $1 \%$ increase in $\mathrm{COHb}$ reduces the measured $\mathrm{DLCO}$ by $\sim 0.8-1 \%$ from both effects $[16,17]$. Using this approach, equation 37 empirically reduces predicted DLCO by $1 \%$ for each percentage point of COHb $>2 \%$.

$$
D_{\mathrm{LCO}}[\text { predicted for } \mathrm{COHb}]=D_{\mathrm{LCO}}[\text { predicted }] \cdot(102 \%-\mathrm{COHb} \%)
$$

A more recent study using an RGA system to measure alveolar carbon monoxide concentration, combined with venous measurement of $\mathrm{COHb}$, found that the effect of carbon monoxide back-pressure and the "anaemia effect" are almost equal and the combined effect is a $2 \%$ decrease in DLCO for each $1 \%$ increase in $\mathrm{COHb}$ [62]. These findings were verified in a discrete sample system [66]. In these studies, where the carbon monoxide back-pressure was measured and used in the calculation of DLCO, equation 38 was used to further correct for the "anaemia effect" where FACOb is the alveolar carbon monoxide fraction in ppm measured at the end of exhalation to residual volume, just prior to the inhalation of test gas.

$$
D_{\mathrm{LCO}}[\text { corrected }]=D_{\mathrm{LCO}} \cdot\left(1+F_{\mathrm{ACOb}} / 560\right)
$$

As endogenous $\mathrm{COHb}(1-2 \%)$ was present in the healthy nonsmoking subjects from whom prediction equations were generated, an adjustment for $\mathrm{COHb}$ is only recommended for interpretative purposes when $\mathrm{COHb}$ levels are known to be elevated or levels above $2 \%$ are suspected. Methaemoglobin (MetHb) will not bind carbon monoxide meaning there is, effectively, a reduced amount of haemoglobin available and leading to a similar "anaemia effect". Since there is effectively less $\mathrm{Hb}$ to bind with carbon monoxide during the DLCO manoeuvre, the measured DLCO is reduced. An adjustment for MetHb has been proposed [126] and is shown in equation 39.

$$
\mathrm{Hb}[\text { adjusted }]=\mathrm{Hb} \cdot(100-\mathrm{MetHb} / 100)
$$

\section{Adjustment of DLco for barometric pressure}

For factors such as $\mathrm{Hb}$ that are related to the individual subject, the recommended adjustment is made to the predicted DLCO value. However, barometric pressure $(P \mathrm{~B})$ is an environmental factor that is 
independent of the individual and therefore the adjustment should be made to the measured DLCO value to simulate standard pressure conditions. The variation in DLCO due to the typical range in high and low pressure cells at a given altitude is approximately $\pm 1.5 \%$. $P$ B decreases with altitude (such that $P_{\mathrm{IO}_{2}}$ decreases) and DLCO increases by about $0.53 \%$ for each $100 \mathrm{~m}$ of increase in altitude. Moreover, the applicability of using a reference value data set from a different location is improved if both the measured DLCO and the predicted value of DLCO are adjusted to standard pressure (760 mmHg or $101.3 \mathrm{kPa}$ ). The adjustment for $P \mathrm{~B}[4,117]$ assumes a $\mathrm{PIO}_{2}$ of $150 \mathrm{mmHg}(20 \mathrm{kPa})$ at standard pressure and can be calculated using equations $40(P \mathrm{~B}$ in $\mathrm{mmHg})$ and $41(P \mathrm{~B}$ in $\mathrm{kPa})$.

$$
\begin{aligned}
& D_{\mathrm{LCO}}\left[P_{\mathrm{B}} \text { adjusted }\right] \approx D_{\mathrm{LCO}}\left(0.505+0.00065 P_{\mathrm{B}}\right) \\
& D_{\mathrm{LCO}}\left[P_{\mathrm{B}} \text { adjusted }\right] \approx D_{\mathrm{LCO}}\left(0.505+0.00488 P_{\mathrm{B}}\right)
\end{aligned}
$$

For $D$ LCO reference values that do not provide $P_{\mathrm{B}}$ data, the altitude of the centre in which the reference values were obtained can be used to estimate $P \mathrm{~B}$ [127] using equations 42 and 43 where a is the altitude above sea level in metres. It should be noted that the relationship between DLCO and $P$ B has not been confirmed using an RGA system. Further research is needed to validate the use of equations 40 and 41.

$$
\begin{aligned}
& P_{\mathrm{B}}[\mathrm{mmHg}]=760\left(1-2.25577 \cdot 10^{-5} \cdot \mathrm{a}\right)^{5.25588} \\
& P_{\mathrm{B}}[\mathrm{kPa}]=101.325\left(1-2.25577 \cdot 10^{-5} \cdot \mathrm{a}\right)^{5.25588}
\end{aligned}
$$

\section{Reporting values}

This document is intended to establish technical standards which, in terms of reporting, will require DLCO systems to be able to report the variables listed in table 4 . It is not intended to specify which variables end users should include in the report forms used in their laboratories, nor is it intended to address the interpretation of DLCO. Although work is ongoing towards establishing a standardised pulmonary function laboratory report form, there is no current standard. A DLCO system must be able to report the unadjusted measured DLCO, the DLCO adjusted for $P_{\mathrm{B}}$, the lower limit of normal and $\mathrm{z}$-score, predicted, and percentage of predicted DLCO, KCO, the lower limit of normal and z-score, predicted, and percentage of predicted KCO. Any adjustments (e.g. for $\mathrm{Hb}, \mathrm{COHb}, \mathrm{PIO}_{2}$ or lung volume) must also be reported along with the data used to make them. The average $V \mathrm{~A}$ must be reported along with the predicted VA (the predicted TLC minus the predicted $V D$ ) and percentage of predicted $V$ A. If available, a separately measured TLC and VA/TLC ratio may be reported, although this is optional. The average VI must also be noted. If a separately measured VC is available, it must be reported to serve as a reference for the adequacy of VI. In addition, comments relevant to the quality of the measurements recorded must be included. A complete list of specifications for which variables and measurements that DLCO systems are able to report is given in table 4. While the use of $\mathrm{z}$-scores is favoured in the interpretation of pulmonary function results, given the continuing use of "percentage of predicted" values in many laboratories, the ability to report both $\mathrm{z}$-scores and percentage of predicted values is recommended.

\section{Specifications for reports and output of results}

Although standardised reporting forms are being considered, manufacturers have diverse options for reporting of results. This is due, in a large measure, to the insistence of various pulmonary function laboratories on having a customised report that matches their historic format. A common option for accommodating electronic medical records, is the provision of a pdf document; however, a universal format for data output in the form of a csv or xml formatted data file has been proposed. This format should include the results and demographic/environmental data for each test in a format that will permit the user to import data to and their own reporting formand export to their particular electronic record. The data file must include all data necessary to calculate the variables listed in table 4. For RGA systems, the data arrays for flow, carbon monoxide and tracer gas must be included and must be adjusted for auto-zero and calibration factors, with the optimal shift applied to the concentration data. Flow data must be converted to BTPS conditions and the data must include the equipment dead-space, the washout volume, the alveolar sample volume, the barometric pressure and the carbon monoxide and tracer gas concentrations at end-exhalation prior to the inhalation of test gas. Manufacturers must provide the format details to permit users to import the data. The complete specifications for the data file are given in the supplementary materials. 
TABLE 4 DLCO reporting requirements

Variable

D.co (unadjusted)

DLco ladjusted for $P_{B}$ )

DLco (LLN and/or z-score)

DLco (predicted)

D.co (adjusted,predicted)

D.co (\% of predicted)

$V A$ (BTPS)

VA (LLN and/or z-score)

VA (\% of predicted)

Kco

Kco (LLN and/or z-score)

Kco (predicted)

Kco $(\%$ of predicted $)$

PB

tBH

V (BTPS)

Fowler (anatomic) dead-space

TLCsb

Reference values source

Test quality grade

Operator comments

Graphs

$\mathrm{Hb}$

$\mathrm{COHb}$

Alternative calculations (e.g. three-equation $D$ Lco, normalised slope of phase III)
Requirement

Required

Required

Required

Required

Optional (required if any adjustments made-specify adjustments)

Required

Required

Required

Optional

Required

Required

Required

Required

Required

Required

Required

Required for RGA systems

Required for RGA systems

Required

Recommended linclude \% variability in

DLco acceptable manoeuvres)

Required (number of manoeuvres, number of acceptable manoeuvres)

Required (full manoeuvre and exhaled gas concentration versus volume with sample

collection indicated for RGA systems)

Optional (required if used to adjust $D\llcorner\mathrm{LC}$ )

Optional (required if used to adjust $D\llcorner c 0$ ) Optional

BTPS: body temperature, ambient pressure, saturated with water vapour; LLN: lower limit of normal; DLCo: diffusing capacity of the lung for carbon monoxide; $V_{A}$ : alveolar volume; $K c 0$ : transfer coefficient of the lung for carbon monoxide; $P$ B: barometric pressure; $t \mathrm{BH}$ : breath-hold time; $V_{\mathrm{I}}$ (BTPS): inspired volume under BTPS conditions; VA (BTPS): alveolar volume under BTPS conditions; TLCsb: single-breath total lung capacity; $\mathrm{Hb}$ : haemoglobin; $\mathrm{COHb}$ : carboxyhaemoglobin; RGA: rapidly responding gas analyser. " : for $D \mathrm{LCO}, V_{\mathrm{A}}, K \mathrm{CO}$, $t_{B H}, V I, V$ Danat and TLCsb the average values from the acceptable and repeatable manoeuvres are reported.

\section{Reference values}

The Global Lung Health Initiative (GLI) is currently working on the development of global reference values for DLCO which will very likely be in a similar structure to the GLI spirometry reference values [128]. Implementation of these reference values requires more complexity than simply inserting coefficients for polynomials and a DLCO system must be able to implement this method of calculating reference values. A list of reference values for DLCO developed using methods that adhere to the 2005 DLCO standards is provided in table 5 [4].

\section{Summary}

It is not the intention of the new standards to render older equipment or instrumentation with alveolar sample chambers or bags, that is still in current use, obsolete. The 2005 ATS/ERS standards address this type of instrumentation. It is recognised that some equipment which meets the 2005 standards will continue to be used but the expectation is that new equipment will meet or exceed the new standards. Some of the systems currently available will be able to meet the new standards with software upgrades.

As already noted, the changes in DLCO standards will not impact the applicability of reference values. In general, pulmonary function measurements are more accurate and precise in normal, healthy subjects than in patients with lung disease so that changes which improve the measurement of DLCO will have less impact on normal, healthy subjects, which favours the continued applicability of reference values derived using older systems. There are already systematic differences among reference value sets for DLCO which are related to the equipment and methodology which impact their applicability. Some reference values 
TABLE 5 Reference values for DLCo from studies that complied with the 2005 American Thoracic Society/European Respiratory Society DLCo standards

\begin{tabular}{lcccc} 
Author $^{\#}$ & Year & Country & Age & Subjects \\
\hline Thompson [129] & 2008 & Australia & $45-71$ years & 498 male/474 female \\
Koopman" [130] & 2011 & Netherlands & $7-18$ years & 278 male/265 female \\
Garcia-Rio" [131] & 2012 & Spain & 65-85 years & 169 male/262 female \\
Kim [132] & 2012 & USA and Australia & $5-19$ years & 225 male/254 female \\
Thomas [133] & 2014 & Denmark & $5-17$ years & male/female 297 total) \\
Michailopoulos [134] & 2015 & Greece & $18-91$ years & 234 male/233 female \\
Verbanck [135] & 2016 & Belgium & 20-80 years & 128 male/124 female
\end{tabular}

DLCO: diffusing capacity of the lung for carbon monoxide. ${ }^{\#}$ : only studies with at least 100 males and 100 females are included. All of these reference values were derived using caucasian subjects. ": test gas contained $19 \%$ oxygen (all other studies used test gas with $21 \%$ oxygen).

currently in use were developed prior to the publication of the 2005 ATS/ERS standards [4]. Hence, there is already a pressing need for reliable, comprehensive reference values for DLCO.

Advances in technology have outpaced guidelines and standards. These revisions to the DLCO standards are required to make optimal use of existing, clinically available technology. Guidelines and standards should not constrain progress in the improvement of pulmonary function measurements but should serve to continually improve the quality of DLCO measurements.

\section{Recommendations for research directions}

In the course of developing these technical standards, the following areas were identified as candidates for research studies to fill knowledge gaps and provide more specific guidelines.

1) Conduct studies of DLCO in normal, healthy subjects in ethnicities other than Caucasian over a wide age range to either validate the use of Caucasian reference values or develop ethnicity-specific reference values.

2) Develop a standardised common report form for pulmonary function testing that can be the default for all laboratories and electronic medical record systems.

3) Determine the effect of barometric pressure on DLCO in normal subjects and COPD patients over a range of pressures reflecting altitudes from sea level to $2500 \mathrm{~m}$ to either confirm or replace equations 40 and 41.

4) Determine the effects of obesity on VDanat, TLCsb and DLCO.

5) Determine whether $\mathrm{Hb}$ measured by skin prick or venipuncture is more appropriate for DLCO adjustment and conduct studies to confirm or revise the relationship between $\mathrm{Hb}$ and DLCO expressed in equations 31 and 32 .

6) Determine normal $\mathrm{Hb}$ levels in populations of different ethnicity and geographical location.

7) Test the proposed DLCO grading scale in large clinical databases for both classical and RGA DLCO systems.

8) Determine the impact of carbon dioxide retention on DLCO measurements.

9) Determine the sensitivity and action levels for the assessment of gas analyser linearity using the dilution of test gas in a calibration syringe.

10) Determine the repeatability of calculating VA and TLCsb by the method in equation 26 which uses all of the tracer gas concentration data throughout the manoeuvre.

In addition to these research directions, there is also a need to update the guidelines for the interpretation of pulmonary function tests in general and of DLCO in particular.

\section{References}

Krogh M. The diffusion of gases through the lungs of man. J Physiol (Lond) 1914; 49: 271-300.

2 Ogilvie C, Forster R, Blakemore W, et al. A standardized breath-holding technique for the clinical measurement of the diffusing capacity of the lung for carbon monoxide. J Clin Invest 1957; 36: 1-17.

3 Graham BL, Brusasco V, Burgos F, et al. Summary: 2017 ERS/ATS standards for single-breath carbon monoxide uptake in the lung. Eur Respir J 2017; 49: 16E0016.

4 MacIntyre N, Crapo R, Viegi G, et al. Standardisation of the single-breath determination of carbon monoxide uptake in the lung. Eur Respir J 2005; 26: 720-735.

5 American Thoracic Society. Single-breath carbon monoxide diffusing capacity (transfer factor). Recommendations for a standard technique: 1995 update. Am J Respir Crit Care Med 1995; 152: 2185-2198. 
Cotes J, Chinn D, Quanjer P, et al. Standardization of the measurement of transfer factor (diffusing capacity). Eur Respir J 1993; 6: Suppl. 16, 41-52.

Forster R. Exchange of gases between alveolar air and pulmonary capillary blood: pulmonary diffusing capacity. Physiol Rev 1957; 37: 391-452.

MacIntyre N. Diffusing capacity of the lung for carbon monoxide. Respir Care 1989; 34: 489-499.

Crapo R, Forster R. Carbon monoxide diffusing capacity. Clin Chest Med 1989; 10: 187-198.

Wilson A, Hearne J, Brennen M, et al. Measurement of transfer factor during constant exhalation. Thorax 1994; 49: 1121-1126.

Leathart G. Steady-state diffusing capacity determined by a simplified method. Thorax 1962; 17: 302-307. technique. J Appl Physiol 1981; 51: 1643-1650.

Weibel E. Morphometric estimation of pulmonary diffusion capacity I. Model and method. Respir Physiol 1971; 11: 54-75.

Forster R, Fowler W, Bates D, et al. The absorption of carbon monoxide by the lungs during breath-holding. $J$ Clin Invest 1954; 33: 1135-1145.

MacIntyre N, Leatherman N, Deitz J, et al. Distribution and uptake of helium, carbon monoxide and acetylene in the lungs during high frequency oscillatory ventilation. Respir Physiol 1986; 63: 201-212.

Comroe JH Jr. Pulmonary diffusing capacity for carbon monoxide (DLCO). Am Rev Respir Dis 1975; 111: $225-228$.

Roughton F, Forster R. Relative importance of diffusion and chemical reaction rates in determining rate of exchange of gases in the human lung, with special reference to true diffusing capacity of pulmonary membrane and issue of blood in the lung capillaries. J Appl Physiol 1957; 11: 290-302.

Michaelson E, Sackner M, Johnson R. Vertical distribution of pulmonary diffusing capacity and capillary blood flow in man. J Clin Invest 1973; 52: 359-365.

MacIntyre N, Nadel J. Regional diffusing capacity in normal lungs during a slow exhalation. J Appl Physiol 1982; 52: $1487-1492$.

Hughes J, Pride N. In defense of the carbon monoxide transfer coefficient KCO (TL/VA). Eur Respir J 2001; 17: $168-174$.

Stam H, Versprille A, Bogaard J. The components of the carbon monoxide diffusing capacity in man dependent on alveolar issue. Bull Eur Physiopath Respir 1983; 19: 17-22.

Johnson D. Importance of adjusting carbon monoxide diffusing capacity (DLCO) and carbon monoxide transfer coefficient (KCO) for alveolar issue. Respir Med 2000; 94: 28-37.

Filley G, MacIntosh D, Wright G. Carbon monoxide uptake and pulmonary diffusing capacity in normal subjects at rest and during exercise. J Clin Invest 1954; 33: 530-539.

Leech J, Martz L, Liben A, et al. Diffusing capacity for carbon monoxide: the effects of different durations of breath-hold time and alveolar issue and of carbon monoxide back pressure on calculated results. Am Rev Respir Dis 1985; 132: 1127-1129.

McGrath M, Thomson M. The effect of age, body size and lung issue change on alveolar-capillary permeability and diffusing capacity in man. J Physiol (Lond) 1959; 146: 572-582.

Newth C, Cotton D, Nadel J. Pulmonary diffusing capacity measured at multiple intervals during a single exhalation in man. J Appl Physiol 1977; 43: 617-623.

Graham B, Dosman J, Cotton D. A theoretical analysis of the single breath diffusing capacity for carbon monoxide. IEEE Trans Biomed Eng 1980; 27: 221-227.

Huang Y, Helms M, MacIntyre N. Normal values for single exhalation diffusing capacity and pulmonary capillary blood flow in sitting, supine positions and during mild exercise. Chest 1994; 105: 501-508.

Stam H, Kreuzer F, Versprille A. Effect of lung issue and positional changes on pulmonary diffusing capacity and its components. J Appl Physiol 1991; 71: 1477-1488.

Stokes D, MacIntyre N, Nadel J. Non-linear increases in diffusing capacity during exercise by seated and supine subjects. J Appl Physiol 1981; 51: 858-863.

Johnson R, Spicer W, Bishop J, et al. Pulmonary capillary blood issue, flow and diffusing capacity during exercise. J Appl Physiol 1960; 15: 893-902.

Smith T, Rankin J. Pulmonary diffusing capacity and the capillary bed during Valsalva and Müller maneuvers. J Appl Physiol 1969; 27: 826-833.

Cotes J, Snidal D, Shepard R. Effect of negative intraalveolar pressure on pulmonary diffusing capacity. J Appl Physiol 1960; 15: 372-376.

Cotton D, Mink J, Graham B. Effect of high negative inspiratory pressure on single breath CO diffusing capacity. Respir Physiol 1983; 54: 19-29.

Cotton D, Prabhu M, Mink J, et al. Effects of ventilation inhomogeneity on DLCO SB-3EQ in normal subjects. J Appl Physiol 1992; 73: 2623-2630.

Cotton D, Prabhu M, Mink J, et al. Effect of ventilation inhomogeneity on "intrabreath" measurements of diffusing capacity in normal subjects. J Appl Physiol 1993; 75: 927-932.

Epler G, Saber F, Gaensler E. Determination of severe impairment (disability) in interstitial lung disease. Am Rev Respir Dis 1980; 121: 647-659.

Viegi G, Paoletti P, Prediletto R, et al. Carbon monoxide diffusing capacity, other indices of lung function and respiratory symptoms in a general population sample. Am Rev Respir Dis 1990; 141: 1033-1039.

Nordenfelt I, Svensson G. The transfer factor (diffusing capacity) as a predictor of hypoxemia during exercise in restrictive and chronic obstructive pulmonary disease. Clin Physiol 1987; 7: 423-430.

Gelb A, Gold W, Wright R, et al. Physiologic diagnosis of subclinical emphysema. Am Rev Respir Dis 1973; 107: 50-63. Rosenberg E, Young R. Potential value of diffusing capacity per liter of lung issue (DL/VA) for early detection of alveolar capillary defects. Lung 1979; 157: 23-29.

Renzetti A, Bleecker E, Epler G, et al. Evaluation of impairment/disability secondary to respiratory disorders. Am Rev Respir Dis 1986; 133: 1205-1209.

Owens G, Rogers R, Pennock B, et al. The diffusing capacity as a predictor of arterial oxygen desaturation during exercise in patients with chronic obstructive pulmonary disease. N Engl J Med 1984; 310: 1218-1221. 
Morrison N, Abboud R, Ramadan F, et al. Comparison of single breath carbon monoxide diffusing capacity and pressure-issue curves in detecting emphysema. Am Rev Respir Dis 1989; 139: 1179-1187.

Gould G, Redpath A, Ryan M, et al. Lung CT density correlates with measurements of airflow limitation and the diffusing capacity. Eur Respir J 1991; 4: 141-146.

Bates D. Uptake of CO in health and emphysema. Clin Sci 1952; 11: 21-32.

Clausen J, Zarins L. In Pulmonary function testing guidelines and controversies: equipment, methods and normal values. New York, Academic Press, 1982.

Quanjer P. Standardized lung function testing. Bull Eur Physiopathol Respir (Clin Respir Physiol) 1983; 19: Suppl. $5,39-44$.

Morris A, Kanner R, Crapo R, et al. In Clinical pulmonary function testing: a manual of uniform laboratory procedures. 2nd edn. Salt Lake City, Intermountain Thoracic Society, 1984.

Cotes J. In Lung function. 5th edn. London, Blackwell Scientific Publications, 1993.

Cotes J. Effect of variability in gas analysis on the reproducibility of the pulmonary diffusing capacity by the single breath method. Thorax 1963; 18: 151-154.

Chinn D, Naruse Y, Cotes J. Accuracy of gas analysis in lung function laboratories. Thorax 1986; 41: 133-137.

Graham B, Mink J, Cotton D. Implementing the three-equation method of measuring single breath carbon monoxide diffusing capacity. Can Respir J 1996; 3: 247-257.

Gardner R, Clausen J, Crapo R, et al. Quality assurance in pulmonary function laboratories. ATS position paper. Am Rev Respir Dis 1986; 134: 625-627.

Glissmeyer E, Jensen R, Crapo R, et al. Initial testing with a carbon monoxide diffusing capacity simulator J Invest Med 1999; 47: 37A.

Hegewald M, Jensen R, Teeter J, et al. Long-term intersession variability for single-breath diffusing capacity. Respiration 2012; 84: 377-384.

Okubo T, Lenfant C. Calibration of gas chromatograph without standardized gas mixtures. Respir Physiol 1968; 4 255-259.

Jensen R, Crapo R. Diffusing capacity: how to get it right. Respir Care 2003; 48: 777-782.

Miller M, Hankinson J, Brusasco V, et al. Standardisation of spirometry. Eur Respir J 2005; 26: 319-338

Miller M, Crapo R, Hankinson J, et al. General considerations for pulmonary function testing. Eur Respir J 2005; 26: $153-161$.

Kendrick A, Johns D, Leeming J. Infection control of lung function equipment: a practical approach. Respir Med 2003; 11: 1163-1179.

Graham B, Mink J, Cotton D. Effects of increasing carboxyhemoglobin on the single breath carbon monoxide diffusing capacity. Am J Respir Crit Care Med 2002; 165: 1504-1510.

Sansores R, Pare P, Abboud R. Acute effect of cigarette smoking on the carbon monoxide diffusing capacity of the lung. Am Rev Respir Dis 1992; 146: 951-958.

Knudson R, Kaltenborn W, Burrows B. Effects of cigarette smoking and smoking cessation on the carbon monoxide diffusing capacity of the lung in asymptomatic patients. Am Rev Respir Dis 1989; 140: 645-651.

Sansores R, Pare P, Abboud R. Effect of smoking cessation on pulmonary carbon monoxide diffusing capacity and capillary blood volume. Am Rev Respir Dis 1992; 146: 959-964.

Zavorsky G. The rise in carboxyhemoglobin from repeated pulmonary diffusing capacity tests. Respir Physio Neurobiol 2013; 186: 103-108.

Wise R, Teeter J, Jensen R, et al. Standardization of the single-breath diffusing capacity in a multicenter clinical trial. Chest 2007; 132: 1191-1197.

Graham B, Mink J, Cotton D. Improved accuracy and precision of single-breath CO diffusing capacity measurements. J Appl Physiol 1981; 51: 1306-1313.

Graham B, Mink J, Cotton D. Overestimation of the single-breath carbon monoxide diffusing capacity in patients with air-flow obstruction. Am Rev Respir Dis 1984; 129: 403-408.

Cotton D, Soparkar G, Graham B. Diffusing capacity in the clinical assessment of chronic airflow limitation Med Clin North Am 1996; 80: 549-564.

J Appl Physiol 1985; 58: 1319-1325.

Jones R, Meade F. A theoretical and experimental analysis of anomalies in the estimation of pulmonary diffusing capacity by the single breath method. Q J Exp Physiol Cogn Med Sci 1961; 46: 131-143.

Chinn D, Harkawat R, Cotes J. Standardization of single-breath transfer factor (TLCO); derivation of breathholding time. Eur Respir J 1992; 5: 492-498.

Ferris B. Epidemiology standardization project (American Thoracic Society). Am Rev Respir Dis 1978; 118: 1-120. Am Rev Respir Dis 1992; 146: 946-950.

Comroe JH. Physiology of respiration: an introductory text. 2nd edn. Chicago, Year Book Medical Publisher, 1974. Welle I, Eide G, Bakke P, et al. Applicability of the single-breath carbon monoxide diffusing capacity in a Norwegian community study. Am J Respir Crit Care Med 1998; 158: 1745-1750.

Fowler WS. Lung function studies. II. The respiratory dead space. Am J Physiol 1948; 154: 405-416.

Stuart-Andrews C, Kelly V, Sands S, et al. Automated detection of the phase III slope during inert gas washout testing. J Appl Physiol 2011; 112: 1073-1081.

Salvador-Ong R, Dijkers E, van Steenwijk R, et al. Single-breath diffusion: comparison between helium and methane as tracer gases in COPD and healthy controls. Eur Respir J 2014; 44: Suppl. 58, P1271.

Cinkotai F, Thomson M. Diurnal variation in pulmonary diffusing capacity for carbon monoxide. J Appl Physiol 1966; 21: 539-542.

Frey T, Crapo R, Jensen R, et al. Diurnal variation of the diffusing capacity of the lung: is it real? Am Rev Respir Dis 1987; 136: 1381-1384.

Sansores R, Abboud R, Kennell C, et al. The effect of menstruation on the pulmonary carbon monoxide diffusing capacity. Am J Respir Crit Care Med 1995; 151: 381-384.

Peavy $\mathrm{H}$, Summer W, Gurtner C. The effects of acute ethanol ingestion on pulmonary diffusing capacity. Chest 1980; 77: 488-492. 

capacity measurement. Chest 2005; 128: 3875-3880. patients with chronic obstructive pulmonary disease. Lung 1999; 177: 263-271.

87 Yang J, Stanton J, Wang L, et al. Effect of salbutamol on the measurement of single-breath diffusing capacity. Respirology 2013; 18: 1223-1229.

88 Baldi S, Fracchia C, Bruschi C, et al. Effect of bronchodilatation on single breath pulmonary uptake of carbon monoxide in chronic obstructive pulmonary disease. Int J Chron Obstruct Pulmon Dis 2006; 1: 477-483.

89 Wanger J, Clausen J, Coates A, et al. Standardisation of the measurement of lung volumes. Eur Respir J 2005; 26: 511-522.

90 Robinson P, Latzin P, Verbanck S, et al. Consensus statement for inert gas washout measurement using multipleand single-breath tests. Eur Respir J 2013; 41: 507-522.

91 Paoletti P, Viegi G, Pistelli G, et al. Reference equations for the single breath diffusing capacity: a cross-sectional analysis and effect of body size and age. Am Rev Respir Dis 1985; 132: 806-813.

92 Knudson R, Kaltenbom W, Knudson D, et al. The single-breath carbon monoxide diffusing capacity: reference equations derived from a healthy nonsmoking population and effects of hematocrit. Am Rev Respir Dis 1987; 135: 805-811.

93 Miller A, Thornton J, Warshaw R, et al. Single breath diffusing capacity in a representative sample of the population of Michigan, a large industrial state. Predicted values, lower limits of normal, and frequencies of abnormality by smoking history. Am Rev Respir Dis 1983; 127: 270-277.

94 Crapo R, Morris A. Standardized single breath normal values for carbon monoxide diffusing capacity. Am Rev Respir Dis 1981; 123: 185-189.

95 Morris A, Crapo R. Standardization of computation of single-breath transfer factor. Bull Eur Physiopath Respir 1985; 21: 183-189.

96 Horstman M, Mertens F, Schotborg D, et al. Comparison of total-breath and single-breath diffusing capacity in healthy volunteers and COPD patients. Chest 2007; 131: 237-244.

97 Graham B, Buchanan P, Withy S, et al. Data acquisition from a multiplex, quadruple mass-spectrometer. Clin Phys Physiol Meas 1985; 6: 17-25.

98 Hughes J, Pride N. Examination of the carbon monoxide diffusing capacity (DLCO) in relation to its KCO and VA Components. Am J Respir Crit Care Med 2012; 186: 132-139.

99 Cotton D, Graham B. The usefulness of KCO is questionable. Am J Respir Crit Care Med 2013; $187: 660$

100 Chinn D, Cotes J, Flowers R, et al. Transfer factor (diffusing capacity) standardized for alveolar volume: validation, reference values and applications of a new linear model to replace KCO (TL/VA). Eur Respir J 1996; 9: 1269-1277.

101 Stam H, Splinter T, Versprille A. Evaluation of diffusing capacity in patients with a restrictive lung disease. Chest 2000; 117: 752-757.

102 Verbanck S, Schuermans D, Van Malderen S, et al. The effect of conductive ventilation heterogeneity on diffusing capacity measurement. J Appl Physiol 2008; 104: 1094-1100.

103 Thompson B, Prisk G, Peytonc P, et al. Inhomogeneity of ventilation leads to unpredictable errors in measured DLCO. Respir Physiol Neurobiol 2005; 146: 205-214.

104 Buist A, Ross B. Quantitative analysis of the alveolar plateau in the diagnosis of early airway obstruction. Am Rev Respir Dis 1973; 108: 1078-1087.

105 Cotton D, Mink J, Graham B. Nonuniformity of diffusing capacity from small alveolar gas samples is increased in smokers. Can Respir J 1998; 5: 101-108.

106 Wanger J, Irvin C. Comparability of pulmonary function results from 13 laboratories in a metropolitan area. Respir Care 1991; 36: 1375-1382.

107 Gaensler E, Smith A. Attachment for automated single breath diffusing capacity measurement. Chest 1973; 63: $136-145$.

108 Punjabi N, Shade D, Patel A, et al. Measurement variability in single breath diffusing capacity of the lung. Chest 2003; 123: 1082-1089.

109 Hathaway E, Tashkin D, Simmons M. Intraindividual variability in serial measurements of DLCO and alveolar volume over one year in eight healthy subjects using three independent measuring systems. Am Rev Respir Dis 1989; 140: 1818-1822.

110 Cooper B, Butterfield A. Quality control in lung function testing. ERS Buyers' Guide To Respiratory Care Products 2009; pp. 24-38.

111 Viegi G, Ferdeghini E, Pistelli F. Single breath diffusing capacity for carbon monoxide: effects of adjustment for inspired volume dead space, carbon dioxide, hemoglobin and carboxyhemoglobin. Respiration 1998; 65: 56-62.

112 Mohsenifar Z, Brown H, Schnitzer B, et al. The effect of abnormal levels of hematocrit on the single breath diffusing capacity. Lung 1982; 160: 325-330.

113 Clark E, Woods R, Hughes J. Effect of blood transfusion on the carbon monoxide transfer factor of the lung in man. Clin Sci 1978; 54: 627-631.

114 Cotes J, Dabbs J, Elwood P, et al. Iron-deficiency anaemia: its effect on transfer factor for the lung (diffusing capacity) and ventilation and cardiac frequency during sub-maximal exercise. Clin Sci 1972; 42: 325-335.

115 Marrades R, Diaz O, Roca J, et al. Adjustment of DLCO for hemoglobin concentration. Am J Respir Crit Care Med 1997; 155: 236-241.

116 Hollowell J, Van Assendelft O, Gunter E, et al. Hematological and iron-related analytes-Reference data for persons aged 1 year and over: United States, 1988-94. National Center for Health Statistics. Vital Health Stat 2005 ; 11.

117 Kanner R, Crapo R. The relationship between alveolar oxygen tension and the single-breath carbon monoxide diffusing capacity. Am Rev Respir Dis 1986; 133: 676-678.

118 Gray C, Zamel N, Crapo R. Effect of a simulated 3,048 meter altitude on the single-breath transfer factor. Bull Eur Physiopath Respir 1986; 22: 429-431.

119 Coburn R, Forster R, Kane P. Considerations of the physiological variables that determine the blood carboxyhemoglobin concentration in man. J Clin Invest 1965; 44: 1899-1910.

120 Viegi G, Paoletti P, Carrozzi L, et al. CO diffusing capacity in a general population sample: relationship with cigarette smoking and air-flow obstruction. Respiration 1993; 60: 155-161. 
Mohsenifar Z, Tashkin D. Effect of carboxyhemoglobin on the single breath diffusing capacity: derivation of an empirical correction factor. Respiration 1979; 37: 185-191.

122 Frey T, Crapo R, Jensen R, et al. Adjustment of DLCO for varying COHb, and alveolar PO2 using a theoretical adjustment equation. Respir Physiol 1990; 81: 303-311.

123 Gaensler E, Cadigan J, Ellicott M, et al. A new method for rapid precise determination of carbon monoxide in blood. J Lab Clin Med 1957; 49: 945-957.

124 Henderson M, Apthorp C. Rapid method for estimation of carbon monoxide in blood. $\mathrm{Br} \mathrm{Med} \mathrm{J} \mathrm{1960;}$ : 1853-1854.

125 Jones R, Ellicott M, Cadigan J, et al. The relationship between alveolar and blood carbon monoxide concentrations during breath-holding. J Lab Clin Med 1958; 51: 553-564.

126 Eckert B, Dimeski G, Isbel N, et al. Methaemoglobinaemia: effect on CO diffusion (DLCO). In Australian and New Zealand Society of Respiratory Science Annual Conference, 2006. http://anzsrs.rewarddesign.net/asm2006/ 005ao05eckertb.pdf. Date last accessed: December 22, 2015.

127 Pressure altitude calculator. National Oceanic and Atmospheric Administration. www.srh.noaa.gov/images/epz/ wxcalc/pressureAltitude.pdf. Date last accessed: December 22, 2015.

128 Quanjer P, Stanojevic S, Cole T, et al. Multi-ethnic reference values for spirometry for the 3-95-yr age range: the global lung function 2012 equations. Eur Respir J 2012; 40: 1324-1343.

129 Thompson B, Johns D, Bailey M, et al. Prediction equations for single breath diffusing capacity (TLCO) in a middle aged caucasian population. Thorax 2008; 63: 889-893.

130 Koopman M, Zanen P, Kruitwagen C, et al. Reference values for paediatric pulmonary function testing: the Utrecht dataset. Respir Med 2011; 105: 15-23.

131 Garcia-Rio F, Dorgham A, Galera R, et al. Prediction equations for single-breath diffusing capacity in subjects aged 65 to 85 years. Chest 2012; 142: 175-184.

132 Kim Y-J, Hall G, Christoph K, et al. Pulmonary diffusing capacity in healthy Caucasian children. Pediatr Pulmonol 2012; 47: 469-475.

133 Thomas A, Hanel B, Marott J, et al. The single-breath diffusing capacity of CO and NO in healthy children of European descent. PLoS One 2014; 9: e113177.

134 Michailopoulos P, Kontakiotis T, Spyratos D, et al. Reference equations for static lung volumes and TLCO from a population sample in northern Greece. Respiration 2015; 89: 226-234.

135 Verbanck S, Van Muylem A, Schuermans D, et al. Transfer factor, lung volumes, resistance and ventilation distribution in healthy adults. Eur Respir J 2016; 47: 166-176. 